Article

\title{
Development and Evaluation of a Mobile Application Suite for Enhancing the Social Inclusion and Well-Being of Seniors
}

\author{
Christos Goumopoulos ${ }^{1,2, *}$, Ilia Papa ${ }^{1}$ and Andreas Stavrianos ${ }^{3}$ \\ 1 Information \& Communication Systems Engineering Department, University of the Aegean, \\ Samos 832 00, Greece; ilias.papas@hotmail.com \\ 2 Dynamic Ambient Intelligent Systems Unit, Computer Technology Institute and Press Diophantus, \\ Patras 265 04, Greece \\ 3 School of Science and Technology, Hellenic Open University, Patras 263 35, Greece; anstavr@hotmail.com \\ * Correspondence: goumop@aegean.gr; Tel.: +30-694-580-9993
}

Academic Editors: Shuai Zhang, Chris Nugent, Jens Lundström and Min Sheng

Received: 12 April 2017; Accepted: 21 June 2017; Published: 22 June 2017

\begin{abstract}
Smart mobile devices, due to their ubiquitous nature and high level penetration in everyday life, can be a key component of an Ambient Assisted Living system to improve the quality of life of older people. This paper presents the development and evaluation of Senior App Suite, a system created for assisting seniors' personal independence and social inclusion. The system integrates mobile computing combined with web and service-oriented technologies to offer a mobile application suite that seniors can easily use to access services, spanning various application areas such as social networking, emergency detection and overall well-being. The research hypothesis is that using such services can be beneficial for decreasing social isolation. There is quantitative indication that this assumption is realistic backed up also by the qualitative analysis from the user's feedback derived during a pilot study $(n=22)$ suggesting that Senior App Suite can motivate people in new activities, maintain connection with social ties, give joy and self-confidence, and increase the frequency and quality of social interactions. Our contribution is a detailed methodology spanning the research, design, development, and evaluation of a solution that aims to improve the quality of life of seniors while addressing open issues identified in related initiatives.
\end{abstract}

Keywords: Ambient Assisted Living; human-centered design; well-being; social inclusion; technologies and ageing; mobile computing; pilot study; ubiquitous computing; service-oriented architecture

\section{Introduction}

\subsection{Background and Motivation}

In 2050 it is projected that the worldwide population of senior adults will be 2 billion [1]. In spite of the fact that life span has increased in modern times, the cost of unsuccessful ageing is important both on healthcare systems and on individual level. In this context, it has been recognized that among the most vulnerable social groups to be more at the risk of social exclusion, a factor of ill-feeling, are the elderly [2]. Therefore measures that can support successful ageing enhancing the social inclusion and well-being of elderly are of great importance.

Social exclusion of elderly is mainly due to the effects of ageing on their health such as mobility problems, chronic diseases and disabilities of any kind as well as due to major developmental life events such as retirement or loss of loved persons. Social embargo may include exclusion from the following [3]: 
- All kinds of social relationships (family and friends);

- Activities of social interest (e.g., participation in voluntary groups);

- Cultural activities (e.g., theatre, cinema etc.);

- Basic services (health services, banking, shopping, public transportation, etc.);

- News and information about daily activities.

Undoubtedly, social exclusion has negative effects on the health and well-being of the elderly [4]. According to a ten years long research study involving 1477 participants in Australia, older people with extensive networks of friends and people they trusted were much more likely to live longer than those with fewer or no friends [5]. The basic conclusion of the research was that powerful social networks can ensure greater survival for elderly people. A related study conducted in UK found that good social relationships are the major contributing factor to quality of life for people aged 65 and over [6]. There is also evidence that social media can play an important role in enhancing social inclusion of older people [7].

In recent years many Information and Communications Technology (ICT) tools have been developed for improving the well-being and health conditions of seniors [8]. Especially in the area of emotional well-being applications that foster social inclusion and services that facilitate communication with family and friends have been proposed $[9,10]$. The use of social networks may help people to stay in touch with old friends and relatives, to see pictures of their grandchildren and have an active participation in group activities by exchanging messages and multimedia content. Robots which usually assist the elderly with activities of daily living tasks have been also designed to enhance well-being by playing the role of a companion [11]. In the emergency detection application area fall detection is of primary importance for the elderly and various types of solutions have been developed based on wearable sensors (e.g., accelerometer and gyroscope), ambient environment (e.g., smart floor) and vision analysis through cameras [12]. On the other hand, cognitive decline related to ageing can be alleviated by applications such as medication reminders, navigators and wandering confronters $[13,14]$.

Therefore there is a growing interest and need to develop services for improved social inclusion and monitoring of the elderly which will improve their well-being by making them more active and social. A concern, however, regarding the access of such services is the difficulties that older people may face. For example, while younger generations are able to use technology in order to maintain their social networks the elderly are still facing technology barriers to access social networking services [15]. In particular, the use of mobile devices has been considered as a convenient tool to access ICT services but for the older people the use of such technology can be an exclusive factor, instead of an inclusive one, if special requirements are not addressed [16]. One way to mitigate these concerns is the introduction of older-adapted devices which are specially designed devices for the ageing hands and eyes [17]. In addition to older-adapted devices, user interfaces for applications targeted to older people should be designed for different capabilities and needs [18].

\subsection{Related Work}

Ambient Assisted Living (AAL) constitutes a fundamental research domain that refers to intelligent systems of assistance for a better, healthier and safer life in the preferred living environment and covers concepts, products and services that interlink and improve new technologies and the social environment, with a focus on older people [19]. In the context of the AAL EU joint program several ICT based solutions for the advancement of social interaction of elderly people have been proposed in order to prevent isolation and loneliness [20]. In the following paragraphs some of the most representative examples are briefly discussed.

The WeCare approach delivered a platform that integrates on-line social networking services and a portal to access services such as events calendar, local news and medication reminder [21]. The objective is to encourage elderly people to participate actively in social networks in terms of enriching their 
social bonding and cohesion and thus improving their well-being. In addition, by supporting the planning of family or informal care to seniors more efficiently, the demand for professional care and social services as well as the associated costs are decreased. A user-centered design approach was followed with the active participation of primary (i.e., seniors) and secondary (i.e., social network peers and caregivers) users who attended interview sessions and workshops. User trials were also performed to evaluate the proposed social networking services in actual use with positive results.

AMCOSOP (Ambient Communication and Sense of Presence) is based on advanced information, communication and sensing technologies to offer a set of personalized services providing elderly a sense of presence of their family, friends, and health care personnel, and assuring that they are never left alone [22]. AMCOSOP combines a software platform for the management of communication services and user information flow as well as home terminal devices with large touchscreens and user friendly interfaces especially designed for the elderly [23]. Through the system and the information that is collected and displayed to the elderly opportunities are provided to decide when to initialize the social connections or to use a service provided by the system or third-parties. Web and mobile client applications have been developed to provide services to users such as displaying recent activities or context information of peers in the same social network.

Go-myLife facilitates accessing of mainstream social networks through a tailor-made platform from which elderly people can invoke typical social networking functionality across a variety of social media platforms [24]. In order to assist seniors at any place and any time mobile computing is used to provide useful context-aware services by taking into account user's preferences. A middleware software layer provides connectivity to social networks by addressing personalization, security and integration-related issues and providing a web based interface. The feedback acquired from the pilot evaluations showed that Go-myLife is a platform that seniors found both easy to use and trustworthy.

Social Interaction Screen (SI-Screen) provides a holistic solution to address the barriers that prevent accessibility of social networks by the elderly [25]. The solution proposed is a combination of a customized hardware device (tablet) with an easy-to-use touch screen, a graphical user-interface specifically designed for elderly people organized in three main areas (i.e., interests, contacts and activities) and a software running on the device for accessing social networks. Through an admin user interface remote technical assistance can be provided to novice users when difficult issues arise such as linking the profile of a user with existing social media sites. The validation of the prototype by seniors found the concept of having an integrated interface across different social networks and the remote assistance appealing.

JOIN-IN helps elderly to escape social isolation by offering a variety of activities such as communication by social networking, multiplayer gaming, exercising through gaming (exergaming) and virtual exercising [26]. In particular, this approach explored how social interactions in online exergaming with the use of persuasive technologies can be used to prevent loneliness and at the same time encourage physical activity. The activities were accessible through PC or TV and a set-top box. Games were designed using the Kinect technology and affording an adaptive game difficulty allowing players with different skill levels to play together. The Join-in system is extensible allowing game developers to register new games and thus enhancing the social and training activities supported by the platform.

SoMedAll (social media for all) is a platform that makes social media easy-to-use through specially designed digital content and a variety of devices and interfaces that are usually available at home (i.e., PC, IPTV, tablet and smartphones) taking into account the capabilities of the elderly [27]. A participatory open web laboratory was used for the research, design, development and evaluation of digital media concepts and services involving people with different lifestyles and living conditions. Several services were developed to support mental and physical well-being.

Elder Spaces focuses on the management of social relations of the elderly in order to provide a platform for improved communication, social activation and interaction [28]. In particular, the proposed approach includes a social networking software platform, which assists people who are not 
familiar with the technology to use tools for improving their quality of life in terms of proposing more recreational opportunities, providing improved health care services and supporting mobility. Furthermore, the platform integrates appropriate sets of information accompanied with semantic annotations to facilitate interfacing with distributed data, operations adapted for social networks and suitable user-friendly interfaces for seniors.

Commercial applications for the support, independent living and social interaction and integration of the elderly have been developed on mobile platforms like Android and iPhone OS. Oscar Senior [29] and Seniors Phone [30] are two examples of mobile computing applications addressed to elderly. Through such applications the elderly are monitored remotely by providing an easy way to communicate with family, friends or individuals involved in their care (e.g., nursing staff). Regarding usability the user interface emphasizes ease of use by seniors which entails the use of large icons and buttons and the provision of simple navigation through custom launchers.

\subsection{Contribution}

While all the presented technologies are credible approaches for the advancement of social interaction of elderly people there are still issues that need to be addressed. First, the use of devices like TVs and PCs, although readily available at home and familiar to most of the seniors can pose limitations with respect to input provision. Furthermore, the design of a web portal solution that is subsequently adapted for mobile devices as identified in some of the examined systems can lead to poor user experience. On the other hand, the mobile specific design approach followed by Senior App Suite ensures an equal good experience for any device type. Moreover, our mobile application suite leverages on technology availability to offer additional characteristics either in terms of extending the user interaction possibilities by exploiting intuitive touch and voice modalities or supporting the provision of value added services by exploiting context information.

Secondly, the provision of customized interfaces to access mainstream social networking systems, as suggested in the reviewed research literature, although it is critical in order to lift some technology barriers for the elderly it specifies only point solutions if not combined with a flexible system architecture to tackle related issues such as unified service and data management. Senior App Suite introduces a service-oriented architecture that incorporates adapted software engineering design patterns to allow modularity, interoperability and flexibility regarding the integration of different social networking platforms and third-party services. In addition, by providing an elaborated social interaction layout built upon a powerful social engine framework it allows for a versatile control of the type of social interactions that seniors may wish to experience.

Thirdly, adopting a user-centered design approach and performing system evaluation are necessary to claim and validate acceptability. Most of the reviewed systems have used focus groups to frame the design and field studies to evaluate the services. Evaluation is typically qualitative based on the feedback provided by seniors during interviews and is limited to assess the acceptance of the provided services. Senior App Suite used several research tools in the design phase (i.e., workshop, focus group, design questionnaire and desk research) to form, validate and explore further the initial user requirements. Most importantly, evaluation was based both on qualitative and quantitative data analysis using valid conceptual models. We have also performed an evaluation to assess the impact of system usage on senior's well-being and loneliness providing evidence on its positive effect.

Consequently, our contribution lies in the addressing of several issues with respect to the above three dimensions, namely technology focus, architecture versatility and methodology setup, spanning the research, design, development, and evaluation of a solution that aims to improve the quality of life of seniors. We argue that our work provides researchers and practitioners in the field of technologies and ageing useful knowledge and an understanding of the fundamental steps required to reproduce such a solution in analogous application cases. 


\section{Methodology}

\subsection{Human Centered Design}

Many researchers have emphasized the importance of involving prospective users in the design process of AAL applications [21,24,25,31,32]. In concert to this culture, our system development was grounded in the principles of human-centered design (HCD) approach [33]. According to ISO 9241-210:2010 [34], HCD aims to find an appropriate allocation of functions between users and technology by establishing a multi-disciplinary design teamwork and following certain iterative activities once the need of HCD has been identified (Figure 1). In this context, a critical aspect of HCD is the active participation of users and other stakeholders in the design activities of the envisioned system.

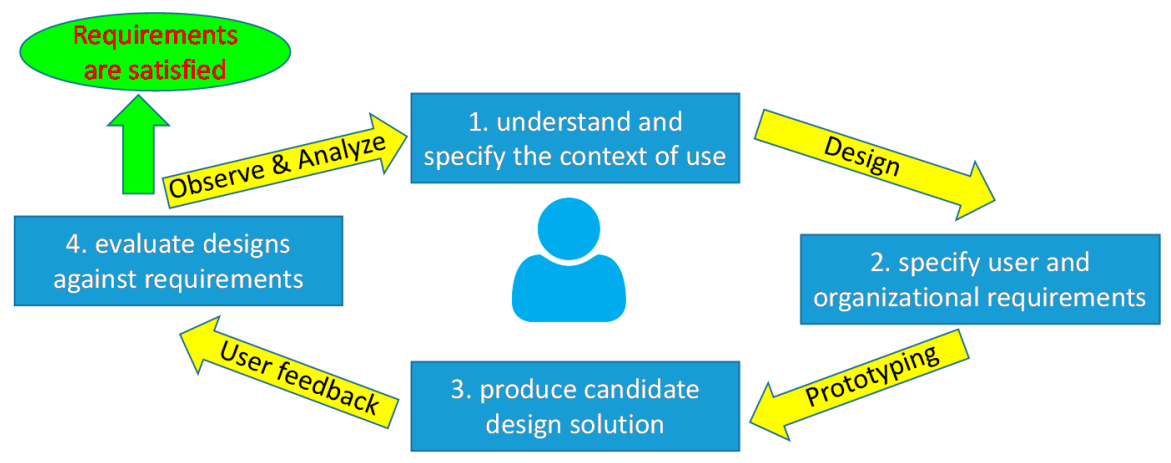

Figure 1. HCD activities.

In our case the involvement of seniors in different development phases from system requirements analysis and design to evaluation was essential in order on the one hand to better capture their real needs and preferences so that the final outcome will be easy to adopt and use and on the other hand to be able to validate system usefulness.

\subsubsection{Research Tools}

The exploration of the practical needs and preferences of seniors was performed by using various research tools such as desk research, face-to-face interviews, focus groups, and on-line questionnaires. As pointed out in the related work section there is a growing interest of the scientific community in the AAL field and many research prototypes have been reported in the literature conveying interesting points on both user requirements and architectural approaches which could serve as a basis for other systems' development. In addition drawbacks and pitfalls identified should be encountered so that they will not appear again in similar situations.

The primary users of Senior App Suite will be elderly adults 60 years old and over with possible age-related issues such as physical and mental abilities decline and feelings of loneliness and isolation. The provision of the developed services may also depend on the assistance provided by family members and friends and in some situations by informal caregivers. The purpose of using such a technology is to support successful ageing by enhancing social inclusion and active participation of the elderly in their communities and providing possibilities to promote their quality of life. Emergency detection in terms of detecting falls is an additional topic of interest.

The HCD process and the subsequent pilot study were organized in Patras, a city in Western Greece with a population of 214,000 inhabitants. The economy of the city mainly depends on the service sector. In the late 1990s, the city suffered a severe problem of deindustrialization, which combined with the consequences of recent economic crisis and demographic changes linked with the aging of the people, caused an increase in the unemployment rate, along with early retired elderly adults. 
In the context of the ELTAB project [35], an AAL project with an objective to enhance the quality of life of elderly people through health-care monitoring and social interaction modules integrated in a single package, a two day workshop was organized with the participation of AAL experts, formal and informal caregivers, welfare and senior associations and citizens. During the workshop inspiring talks were given by the organizers to initiate collaboration and participative discussions where the attendees discussed in open and friendly atmosphere the daily life and social problems of seniors and their needs in the areas of healthcare monitoring, social-inclusion and general well-being.

The following areas were identified as important to be considered in designing a system that assists seniors in their daily life:

- Lack of connectedness with others: The elderly are at a higher risk of being alienated from the rest of society and live in solitude. One factor is the replacement of the extended family model with the nuclear family model combined with the heavy working schedules of seniors' offspring. Another important factor that may intensify isolation is seniors' vulnerable health and motor difficulties which may prevent them from frequently getting out from their home and being in contact with other people, such as relatives, friends and acquaintances.

- Memory loss: Ageing leads to memory problems that may range from a mild level e.g., forgetting names, phone numbers and misplaced objects to a more severe one e.g., forgetting to take medicines or attending a scheduled activity or giving directions to get at home. Staying social, physical and mental exercising, managing stress, sleeping well and eating healthy food can improve memory and cognitive skills.

- Falling incidents: Elderly people are particularly vulnerable and prone to falls. Approximately one third of the elder population falls at least once per year [36]. Many falls (70 to 80 percent) do not result in injuries [37]. Approximately half of the non-injured fallers require assistance in order to get up and for those incidents the period of time required until the aid is provided often influences their health consequences. Therefore, in case of a fall it is essential to have someone for assistance or be immediately notified.

- Access to social care services: Due to health issues the elderly often need assistance on a variety of everyday activities, such as cleaning, cooking and shopping along with informative support on activities such as meeting with others and participating in social and leisure events. In this context, various social care services are usually provided by the state or non-governmental organizations. Providing information on what social services or care centers are available and facilitating their access is useful for the elderly.

Following the workshop workings several potential users were contacted and interviewed and a focus group of eight seniors satisfying the profile of Senior App Suite users was established. The aim of the focus group was to explore the limitations and constraints of seniors on using technology products and to analyze the expectations of the seniors on the requirements that the application suite should meet in order to be accepted and used. Some of the user expectations identified are:

- An easy way to contact friends and relatives.

- An SOS button to notify family in case of an emergency.

- A simple way to find cultural events on the Internet.

- I would like to get informed on welfare services provided in my city.

- Pension information will be good to have.

- An easy medium to notify family members on my planned activities.

- A friendly way to track the news I'm interested to.

- In the last six months I fell twice. I need an easy way to notify my son in such a case.

- Due to chronic health problems I get many medicines on a daily basis. I need a reminder because I' $m$ forgetting sometimes.

- I like new technology but it is difficult to use. I need an easy way to find and use what I want. 
- I would like to know other people with similar interests.

- I have vision problems. So I can't read text on screen. Voice notifications will be good to have.

The information gathered from the workshop and the focus group was used to specify initial user requirements and to define the services to be included in the Senior App Suite. The articulated requirements provided information on what kind of applications the targeted users may need and would like to use in order to promote their autonomy, social inclusion and well-being.

\subsubsection{Design Questionnaire}

To extend our system analysis and design process it was considered important to validate and explore further our initial findings by involving a wider user group. This approach involved the design of a questionnaire addressed to a wider audience in an attempt to justify the initial conclusions and to better interpret the findings from the workshop. An on-line questionnaire was defined including closed questions with a typical 5 point Likert scale, multiple choice questions with predefined options and open questions with mandatory or not completion (Appendix A). The questionnaire items were defined and tested during the course of the qualitative methods applied, providing in this way content and face validity.

The design questionnaire was completed by 69 older adults (aged 60 and over), 27 male (39.1\%) and 42 female $(60.9 \%)$, within a period of three weeks. The average age was $66.2( \pm 4.9)$ years and approximately one third of the sample $(32.2 \%)$ was assisted by a relative or friend who completed on their behalf the on-line questionnaire as indicated in a relative field of the questionnaire. Besides using focused social network groups [38-40] as the main channel for questionnaire dissemination our participation in the AAL workshop was utilized. In addition to demographics (Figure 2) the participants considered the usefulness of a system which integrates a variety of services (e.g., social networking, news, events calendar, gaming, e-payments, fall and emergency detection, medication reminder, etc.), in an integrated application suite or a web portal with consistent and easy to handle user interface in order to confront the difficulty of searching them throughout the plethora of applications and settings offered by the modern mobile operating systems. The majority $(80.7 \%)$ of the participants responded that strongly agree or agree, which underpins the need for the development of a system with a user-friendly interface, hiding the complexity that creates technology fear, confusion and barriers in social groups, such as the elderly. At the same time, the need for grouping useful services and features was expressed.

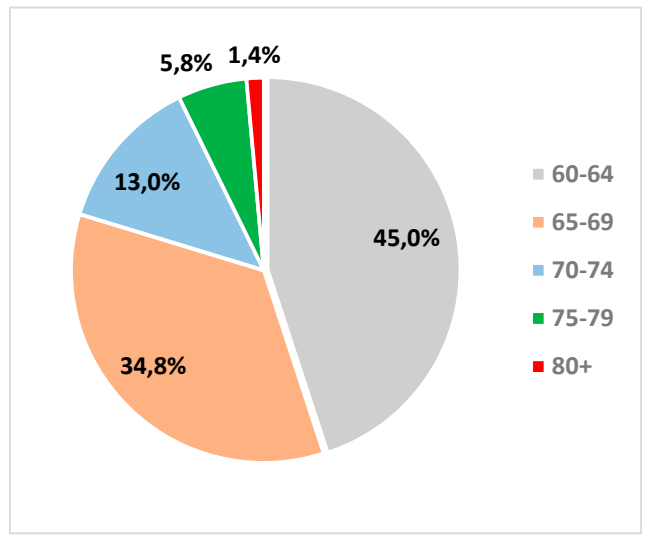

(a)

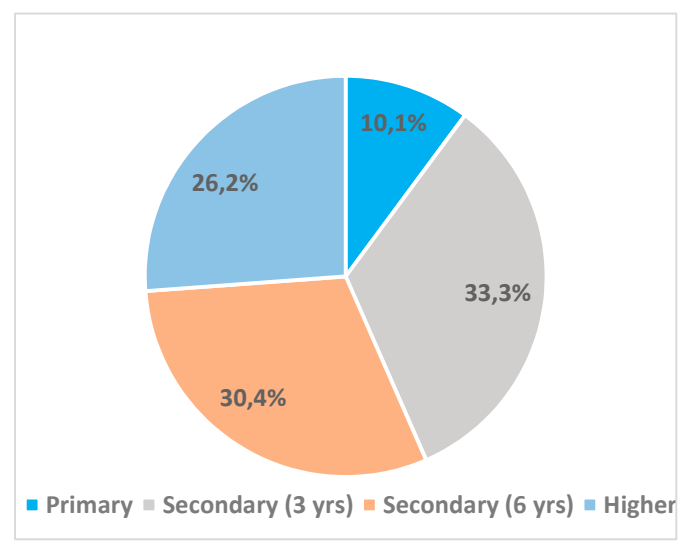

(b)

Figure 2. Age distribution (a) and education level (b) of the 69 participants.

Figure 3 presents the expressed preference on the envisioned system services by the participants. On the top of the list we found fall detection and subsequent notification of relatives or friends, reminders of activities and medication and accessing of social networks and news. Additional services 
it was possible to be proposed by the participants through an open type question. Most of the suggestions were types of activity reminders such as paying various bills, car servicing and pet vaccination. Our findings regarding the prioritization of system services are analogous to ratings on the reasons of using a mobile device reported by other studies [16,41], where security and safety are considered first, followed by personal communication, information seeking, business transactions and entertainment.

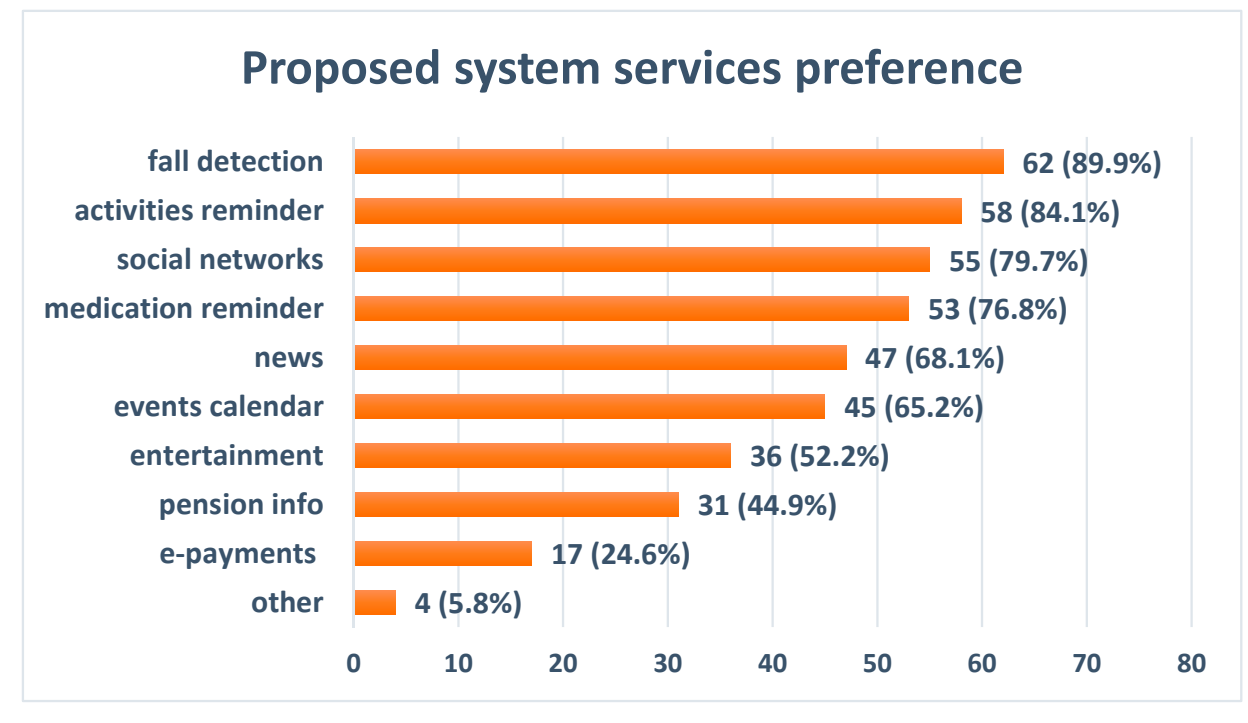

Figure 3. Expressed preference on the proposed services.

Another section included questions about user interface features that should be integrated in elderly assisting applications. The features that were mostly qualified by the responses were the following:

- Large size icons, menus and text to be easy to navigate and handle the application.

- Simplified layout and suitable content to facilitate accessing (e.g., avoiding zoom in/out or extensive scrolling) and comprehension.

- Simple and clear interface regarding the access of basic functionality.

- Accessibility and customization options provided to the user e.g., changing the font size, user interface themes, etc.

- Integration of sound notifications in combination to visual notifications when the application provides feedback to the user (e.g., an error indication).

- Support of voice commands.

Finally, the participants were asked to select the type of mobile device that would prefer to use with an assisting application. The choices were Tablet, Smartphone or Both. The majority of the participants $(65.2 \%)$ selected Tablet with Both being the second choice $(29 \%)$. This is justified by the fact that tablets with a screen size over 10 inches are considered most suitable devices for applications targeted to elderly. On the other hand, the mobility of smartphones for some older adults is considered of equal importance.

\subsubsection{Summary}

To summarize, the HCD process provided the following contributions to system analysis and design:

- Specification of user requirements for the needed services that could assist the well-being and social inclusion of seniors based on the interactions with the involved stakeholders. 
- Prioritization of the envisioned system services, for instance fall detection, activities reminder and sharing experiences were found to be more preferable than e-payments and gaming.

- Specification of user interface design requirements that would improve the usability of the application suite and its various functionalities.

- Additional ideas for service design such as the personalization of the provided services based on user profile information (e.g., preferences, location, and calendar activities) or the generalization of services (e.g., reminders of tasks in general and not only medicine).

- Understanding the characteristics and limitations of seniors as users of the technology and clarifying the technology role in terms of possibilities and barriers in supporting seniors' daily activities.

\subsection{Accessibility}

In order to achieve an effective human-computer interaction the design of the user interface has to consider the needs and constraints of the target users [42]. Ageing will often lead to both cognitive and physical negative changes, like visual auditory, memory and learning decline [43]. For example, visual decline entails less sensitivity to contrast, color and glare as well as decline in peripheral vision. Existing software interfaces, particularly on mobile devices, are not considered senior friendly $[16,44]$. In that respect, reducing the complexity of applications or human-computer interaction for elderly users could be essential for the design and development of mobile applications [45]. Therefore, designers should focus on simple, clear and consistent design, and use large font size and sharp contrast between background and font color.

When matching these design requirements with the feedback of our elderly focus group and recommendations of the literature [46-48] the following design guidelines emerge:

- Text readability: use font size of 36-48 pt. on mobile apps (or 14-18 pt. on web apps) and sans serif style (e.g., Arial, Verdana), avoid special styles (italics, underline, all caps), important information should be highlighted, use common language and provide the ability to alter font and text properties by the end-users.

- Simple layout structure: use simple and consistent design and layout, use left-aligned text, constant spacing between words and line spacing of 1.5 lines, avoid large blocks of text and text over images and group together related topics.

- Sharp contrast between background and font color: an example is black text on white/yellow background or the opposite, customization can satisfy different user preferences, avoid different background colors.

- Information accessibility: provide text alternatives (e.g., audio for visually impaired users), provide users enough time to read and use content, provide ways to help users navigate to the content of interest, help users avoid and correct mistakes, use text instead of images of text in web content.

- Minimize text input: Text fields should be replaced with other forms of input such as radio buttons or lists so that users select their choices instead of typing.

- Continuous assistance: A help button should be present in every activity window in order to provide information and examples pertinent to the interaction of the user with the content.

Figure 4 shows the design of two configurations of the main menu screen of the Senior App Suite with varied functionality emphasizing the simple layout structure and the use of large icons and text. The idea is that novice users can start with limited functionality and simple user interaction where as more advanced users can enable more services as they like. Furthermore, the information stored in the user's profile is taken into account by the system so that the user interface presents information that may interest the user e.g., news, channels, and shopping recommendations. 


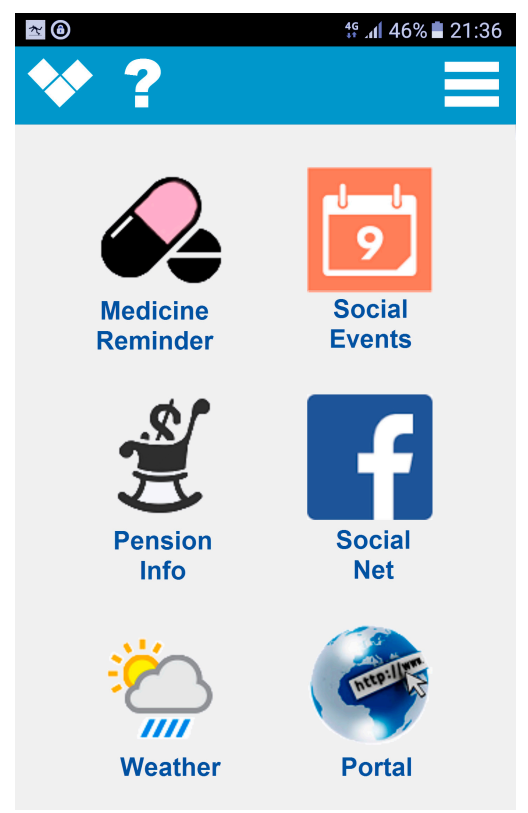

(a)

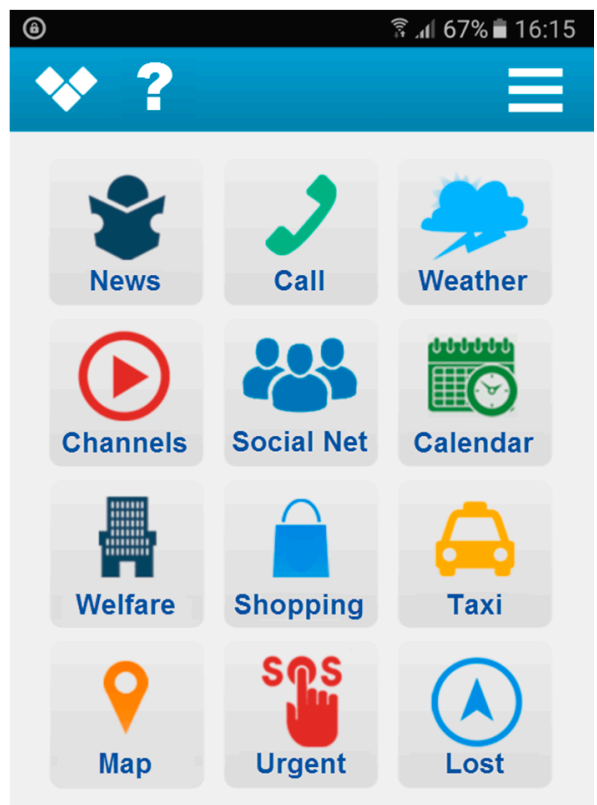

(b)

Figure 4. Service-centric views of Senior App Suite with (a) basic features and (b) more rich features.

\subsection{Services}

\subsubsection{Social Networking}

Existing user interfaces of web applications and social networks that display information streams of interest to the elderly although they may have been designed with basic accessibility criteria in mind they generally provide complex user interfaces that are not appropriate for most of the elderly. As a consequence, we are replacing their standard graphical user interface with a fully customized user interface for our target users. Figure 5 shows the streamlined user interface to access social network (i.e., Facebook) content for interaction with family and friends. In this context, Senior App Suite views Facebook as a system of objects and relationships between them and not as a set of web pages or application screens to be imported. This also implies that the user has granted the permission to access his/her account. The typical development steps of a Facebook application have been followed to build such a customized interface [49].

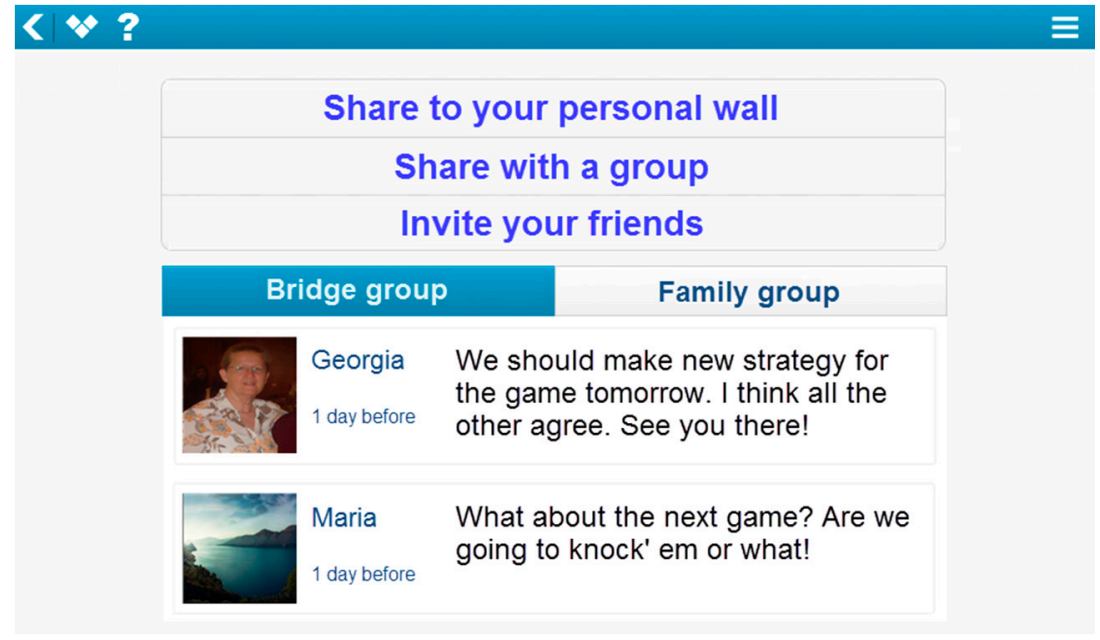

Figure 5. Social network access from Senior App Suite. 
Based on the feedback we received from our focus group, another issue related to the social networking potential of the elderly is the fact that many seniors do not have an account on mainstream social platforms and they hesitate to create one due to the complexity of the process and due to privacy concerns. There are also cases that different seniors may have accounts in different platforms making their interaction problematic. In this context, providing an intermediate facilitator service for seniors to socially interact without using the complicated user interface designs of different vendors or even having to create an account on a platform that a friend is using would be well accepted.

Senior App Suite provides a user-friendly interface which can display content gathered by social networking platforms transparently to the user. In particular, the user can view the status, comments and multimedia content (text, photos, and videos) of their socially bonded peers. The user can interact with this context and provide feedback to the user which will be displayed on the external social networking platform depending on the capabilities provided by the platforms' Application Programming Interface (API). Figure 6 shows the user interface for social interaction of a person with family and friends. The user is able to browse a timeline view to see messages, activities and shared content like personal photos and videos. In addition, communication services are provided such as video calls, sending photos/videos and messages to interact with a selected person.

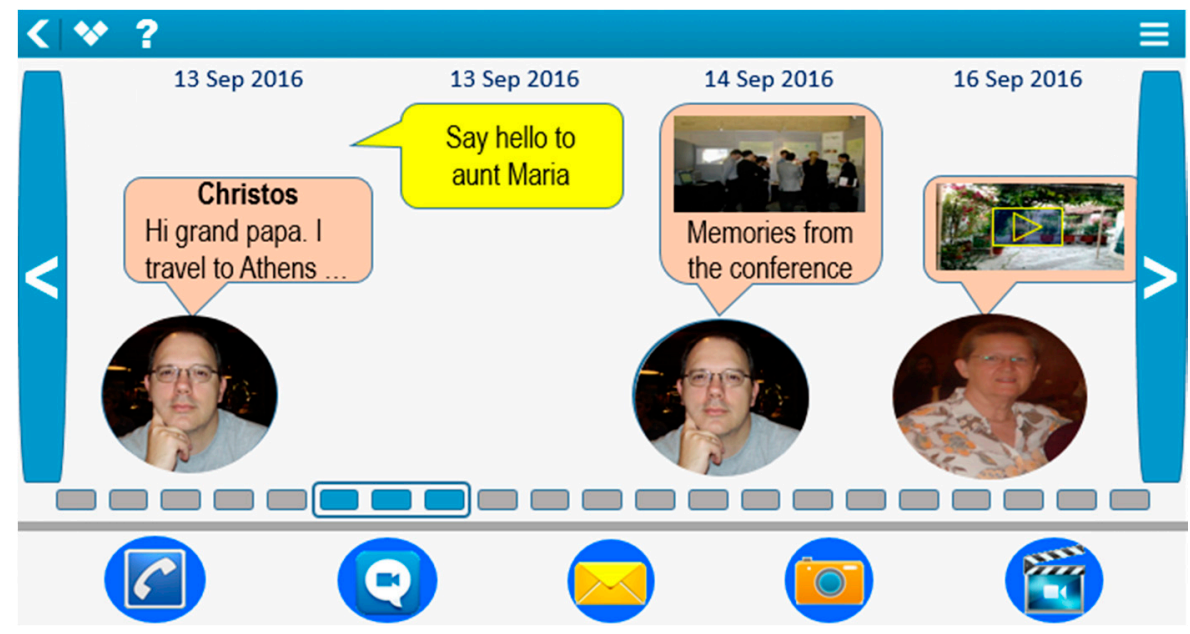

Figure 6. Timeline-based information shared by a person with family and friends.

\subsubsection{Activity/Medicine Reminder}

For most elderly people medication treatment is essential and is part of their daily life, especially if they suffer from chronic medical diseases. At the same time, adherence to medication schedules may become a problem due to memory decline especially for seniors who suffer from dementia or Alzheimer's disorder. When medication doses are skipped, or taken repeatedly the health consequences can be severe. Therefore a reminder service to take medicines especially in the case of people who live alone can assist the effective management of their treatment, thereby improving their quality of life and contributing to the achievement of well-being. Besides medication the reminder service can be used to remind activities and tasks that seniors need to do in a scheduled base or only for once. The use of mobile technology allows using the application even when the senior is moving away from the home, for example, during their vacations. Figure 7 shows part of the user interface of the reminder service. According to the user interface guidelines for senior users the screens contain large buttons and clear titles using large font size, to facilitate browsing and configuring the service. For the novice or cognitive declined user, however, configuring such a service may require the support of a relative or a friend who is more capable with forms completion. 


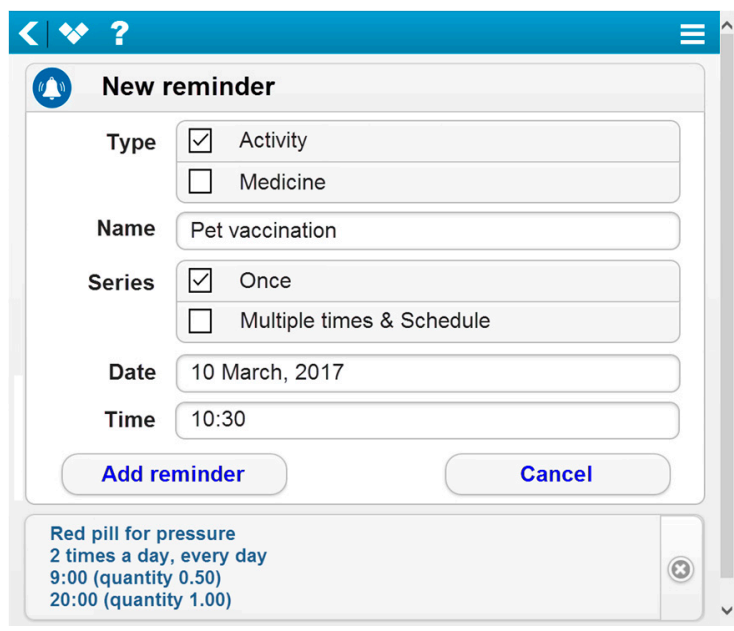

(a)

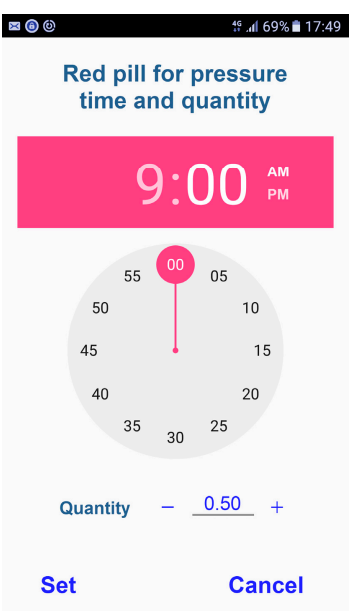

(b)

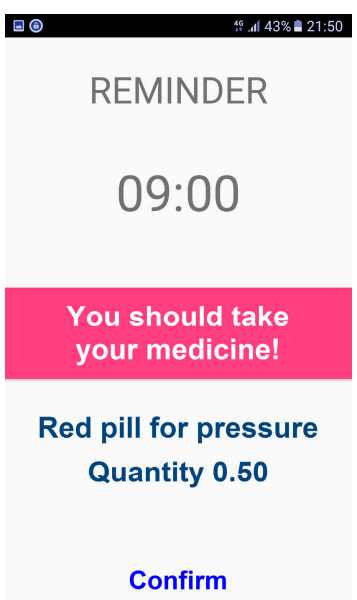

(c)

Figure 7. Reminder service screens of Senior App Suite (a) new activity reminder definition (b) setting time and quantity for a medicine schedule and (c) receiving a reminder alert.

\subsubsection{Fall Detection}

Fall detection applications can assist seniors by instantly notifying relatives, health services or other specified persons. The fall detection service implemented can be activated through the corresponding switch in the application suite settings screen (Figure 8a). The service as soon as it detects a fall it displays a confirmation message with a sound notification to the user. The idea is that in case of a false detection (e.g., the device has accidently dropped) the notification can be aborted (Figure $8 \mathrm{~b}$ ). In case of a true detection the notification can be either immediately confirmed by the senior or when the user is not able to respond, the notification will be automatically sent by the application $3 \mathrm{~min}$ after fall detection. Depending on the defined settings the application will call and/or send a short message (SMS) to the emergency mobile phones specified.

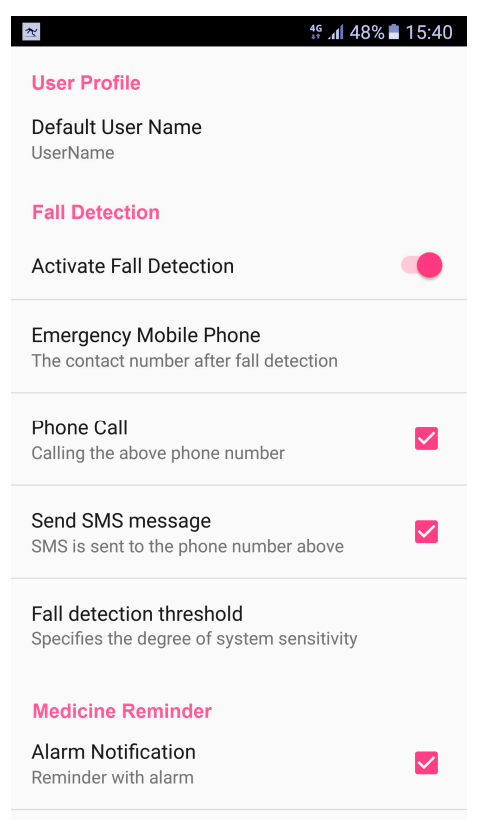

(a)

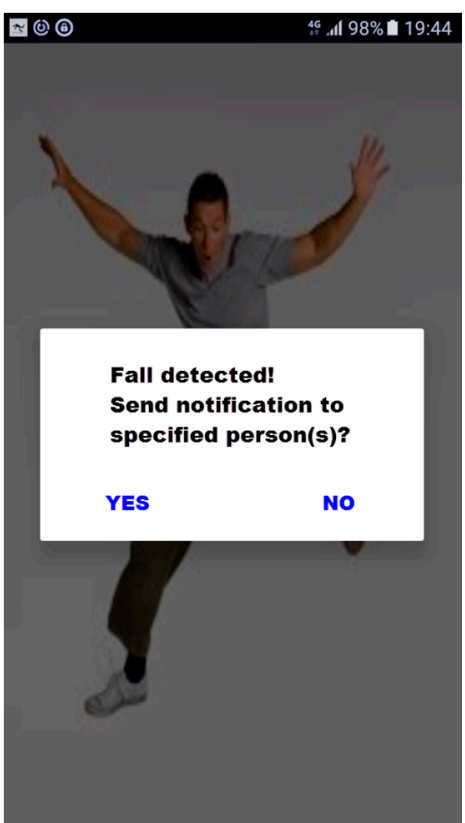

(b)

Figure 8. (a) Activation of fall detection service in settings screen; (b) Sending notification to specified person(s) confirmation message. 
The fall detection service is based on the measurements provided by the 3-axis accelerometer sensor of the mobile device and by checking the calculated gForce value (Figure 9a).

The state diagram of the fall detection algorithm is shown in Figure 9b. Based on the acceleration signal pattern describing a fall, a threshold value of $2 \mathrm{~g}$ is defined for detecting falls in two steps. First the algorithm moves from "NORMAL" state to "POSSIBLE FALL" state in the event of the current measurement being equal or above the defined threshold. If the acceleration value is below or equal to $1 \mathrm{~g}$ for the next $10 \mathrm{~s}$ then the state is set to "FALL DETECTED", otherwise to "NORMAL". It hould be noted that for the first $4 \mathrm{~s}$ after a possible fall detection the measurements are deliberately ignored as the mobile device may not had been stabilized yet after the initial contact with the ground. After fall detection the algorithm sends the notification message(s) unless the user aborted the process. The threshold value has been defined empirically and it should be noted that since the precision of the sensor measurements may vary from device to device a calibration process may be required before the appropriate threshold value is set to the settings screen.

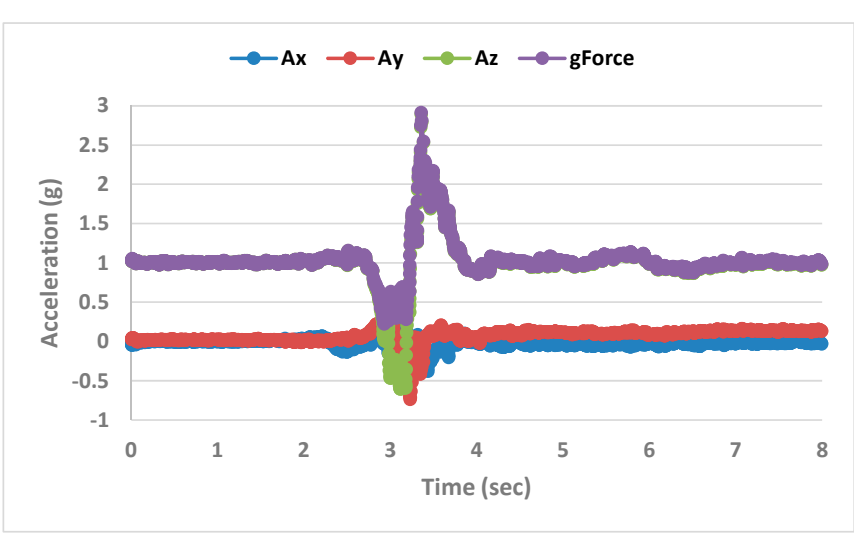

(a)

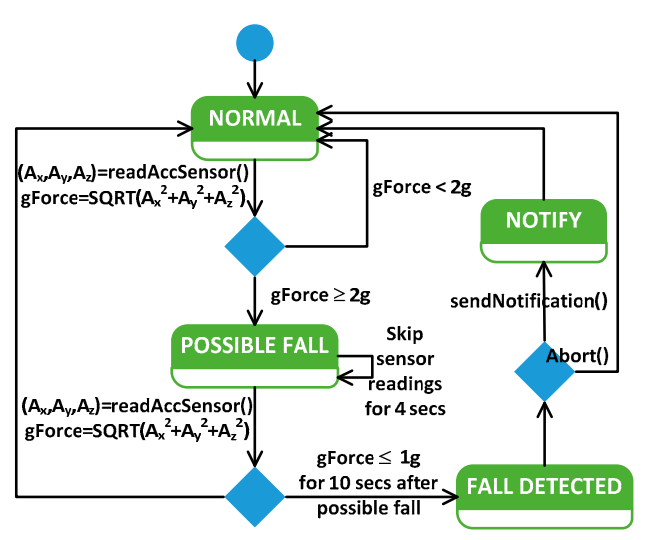

(b)

Figure 9. (a) Acceleration signal variance during a fall incident; (b) fall detection algorithm state diagram.

False fall detections may appear occasionally when the user moves from a sitting to a standing position quickly. However, in this case the acceleration signal will be usually less than $2 \mathrm{~g}$ on its maximum value for our target user group. Furthermore, the standing-up signal has opposite components compared to the falling i.e., the increasing wave comes first and the decreasing wave next. To alleviate in any case this problem a simple extension of the algorithm is applied to check whether in $1 \mathrm{~s}$ timewindows the maximum value appears after the minimum.

\subsubsection{Information}

In this category a number of various topics are covered as described below. Figure 10 shows representative screens of the provided information services.

Welfare: The user has access to information related to welfare services provided by governmental and non-governmental organizations in the administrative district area of seniors' residence such as help at home, open care centers, daily care centers, and friendship and solidarity centers. The user is provided with basic information and the ability to communicate with agents of the welfare services in order to apply for an available social program or request to be notified for a future program.

News: This service provides the latest news classified in various categories such national, world, politics, culture, health etc. using available on-line news sources.

Channels: This service provides access to selected Youtube channels that are related to seniors. Usually these are videos that encourage certain vulnerable groups giving advices for an easier everyday life and attempt to pass messages of optimism and self-confidence. 
Weather: Weather forecast is provided for the users' current location based on available weather web service providers.

Social events: Based on senior's home location and specified preferences the service displays social events, courses, lectures, conferences, etc. to be carried out in the wider region. The search radius is configurable and the default value is $10 \mathrm{~km}$. For each event its title, location and date are displayed. By tapping on an event the location and the route to the place are provided on a map.

Maps: This service is based on Google's Maps and Geolocation API in order to provide navigation features upon user's request. In combination with the "Lost" service it provides, especially to seniors with memory problems, detailed guidelines on the appropriate route to return safely at home using the address specified in the user's profile. In the same context upon user's acceptance the application can notify senior's relatives/friends with his/her current position which can be displayed to a map. Finally, seniors with mobility problems can look for nearby accessible places, or even add themselves an accessibility point in order to inform other peers.

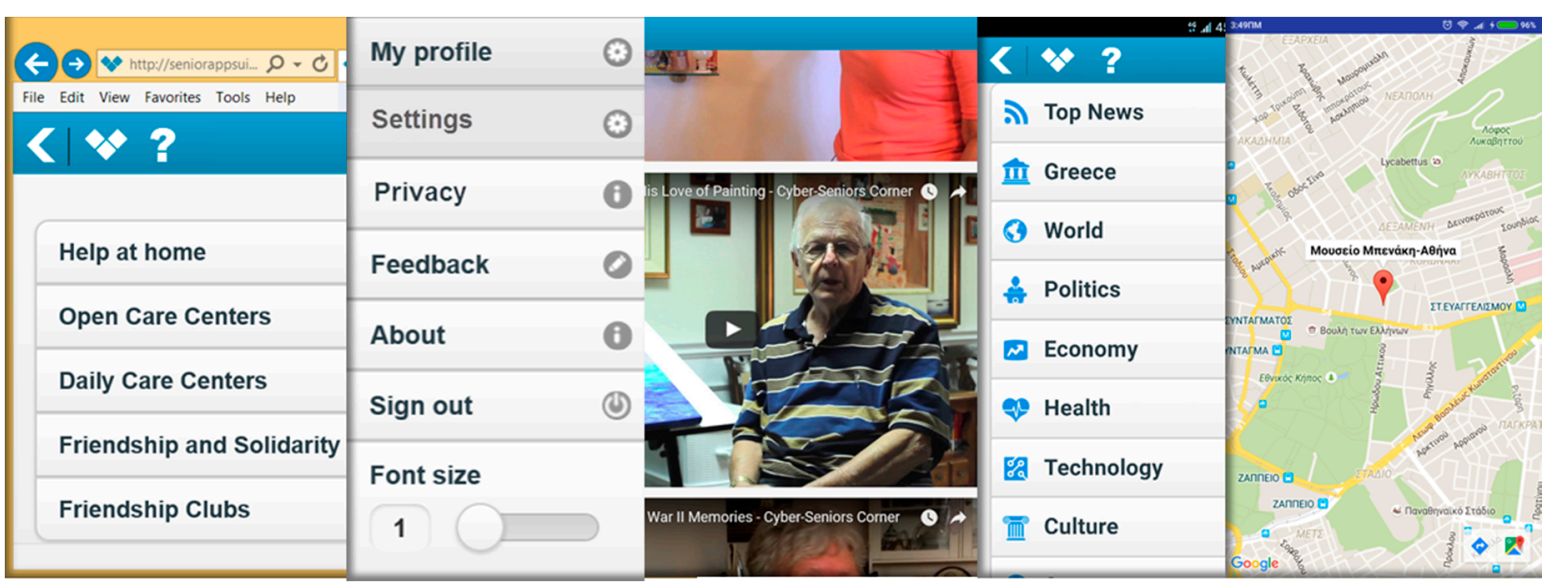

Figure 10. Screens of information services.

\subsubsection{Everyday Activity Facilitation}

The Senior App Suite offers a number of services to facilitate ordinary activities such as calling, shopping, commuting and gaming. For example, an easy accessed phonebook with handy phone numbers for transportation services is provided, the user can book a taxi by calling a taxi service available at user's location, order supplies from the local supermarkets with home delivery and pay bills with bank e-Payment services (Figure 11). In addition, the user can redirect to Senior App Suite portal to access entertainment services such as memory games.

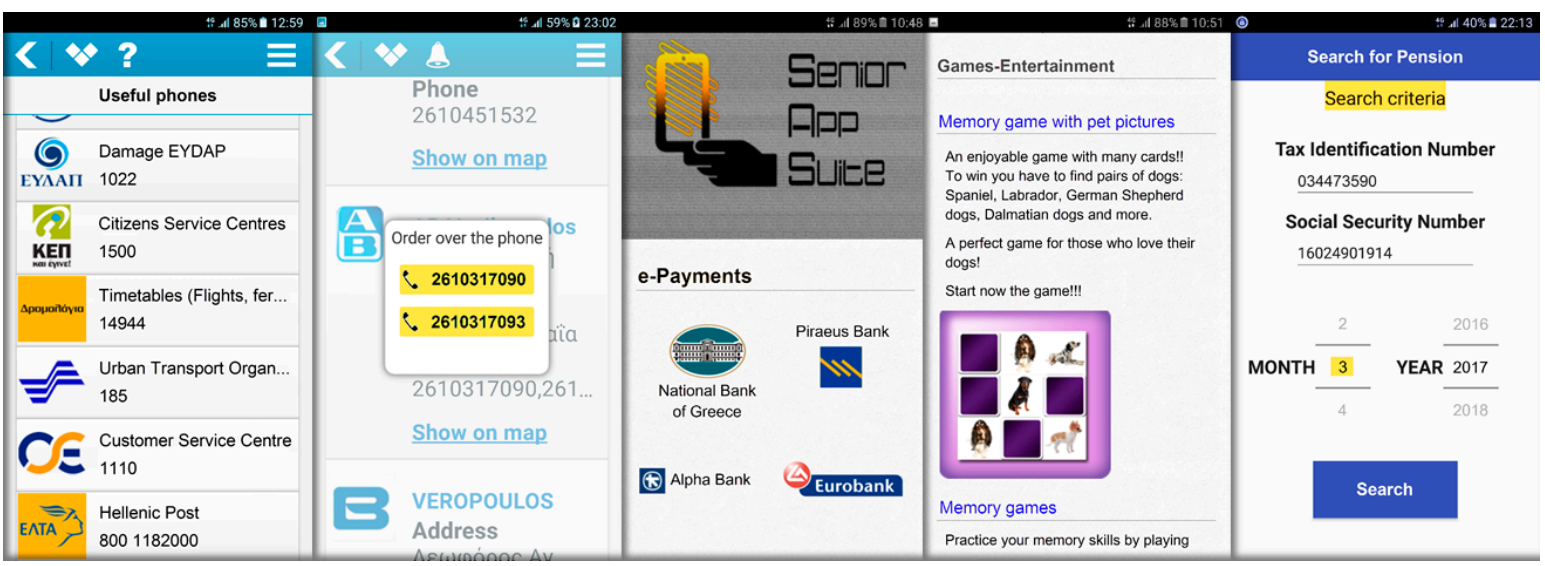

Figure 11. Screens of everyday activity facilitation services. 


\subsubsection{Special Purpose}

Finally, two special purpose services are provided. The first one informs seniors on their total monthly pension compensation. Providing such a service came as a requirement from the design questionnaire analysis (44.9\% of the participants responded positively). Moreover, the service necessity is also confirmed by our experience working at the pensions department of the Greek Social Security Electronic Government (GSSEG) (one of the authors is employed in this department). A large proportion of the incoming calls at the department's call center concerns inquiries on the date and the exact amount of the pension payment. The situation has been aggravated due to the on-going restructuring of the social security system in Greece. Even though most of the pension funds have developed electronic information services providing informative pension sheets, their separate access by the pensioners is difficult since each of them requires an identification process that may vary considerably. Even providing the visual confirmation code (i.e., captcha) becomes a problem because this is deliberately made obscure. Therefore for an older adult whose pension income splits to different pension funds (subsidiary, widow etc.) the whole process is complex and tedious.

Considering all the above, a service is provided where the user is required just to select the month and year and press the "Search" button (Figure 11, last screen). The service requires also the Tax Identification Number and Social Security Number which come pre-filled given that they were provided during user's profile creation. Upon a successful search a window displays the list of the pension elements with the payment amount and date as well as the bank that the beneficiary holds an account which will be credited. The implementation involves consuming a web service that is provided on a secure channel by the GSSEG. A combined query is performed on the server's database and a JavaScript Object Notation or JSON formatted message is returned to the client with the results. For data safety, the activation of this service is managed with the entry of a secret key that is given to the user after his/her identification.

The second service is an emergency (SOS) button displayed in the main menu screen of the application suite which when pressed sends a message containing the location of the senior to the specified friends. A cancelation time window is provided to avoid false activation.

\subsection{Service-Oriented Architecture}

The developed system is based on a Service-Oriented Architecture (SOA) that imposes a separation of concerns between service interfaces and implementation [50]. The SOA approach has been largely used as a convenient architectural style to implement dynamic, extendable and reconfigurable systems. Different services can communicate using open communications protocols and exchange data using standardized interfaces in a way that is transparent to the underlying execution platform. Services can be enabled or disabled dynamically without impacting application operations and can interact with each other in a meaningful way, which results in an overall application behavior.

Figure 12 illustrates the system architecture and its main components. The architecture follows a three-tier client/server model where the server has the domain name SeniorAppSuite.org and hosts the portal functionality. The client side is implemented either as a desktop web application providing access to social interaction and third party web services (e.g., news, weather, pension information, e-Payments, etc.) or as an Android application which additionally provides fall detection, emergency alerts and voice notifications by using the Android TextToSpeech API for instance when a medication/activity reminder must be provided.

The database tier stores all the Senior App Suite related data in a MySQL relational database, such as user profile information, social networking data, event calendar, phonebook, etc. On the mobile device active user data are stored in an SQLite database so that even when temporarily there is no network connection the user can still use the application. When the user exits the application the user entry is deleted from the SQLite database. 


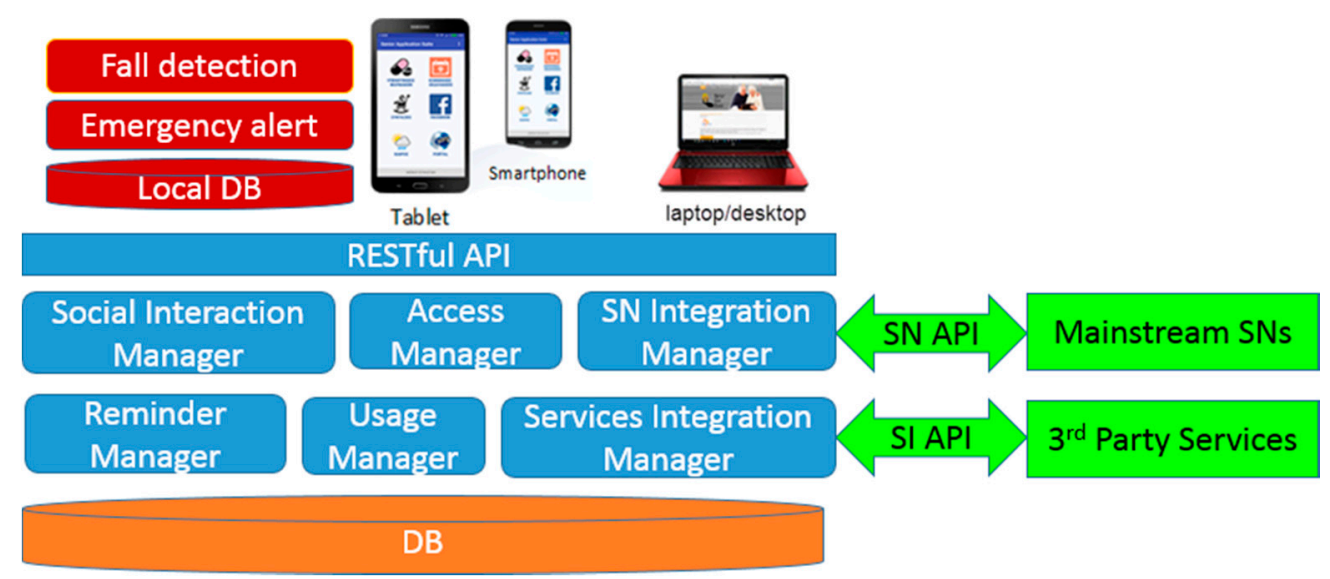

Figure 12. System architecture.

The client/server interaction is based on a Representational State Transfer (REST) or RESTful interface that uses HTTP POST/GET requests to access the functionalities offered by the client user interface and implemented on the server. The following modules are implemented at the server side.

The Social Interaction Manager (SIM) is responsible for seniors' social interaction and was developed based on the Elgg framework [51]. Elgg is a prevailing open source engine to develop social networks following a modular structure and allowing the integration of a large set of plug-ins and add-ons developed by the Elgg community [52]. A key feature of this framework is a versatile set of access controls that facilitates imposing a variety of privacy policies. The dynamicity of the environment allows for setting access permissions on a fine-grain level allowing a post to be shared to a specific group of friends and the next one to be shared with all the participants of a network.

Although Elgg provides a default menu organization based on tools we have restructured the layout of the portal in accordance with our target groups' identified requirements. The following menus are thus provided:

- Personal: timeline-based information shared by a person with family and friends, options to publish new content and manage profiles and settings.

- Social network: timeline-based information shared within one's network and options to search and connect with new peers.

- Groups: timeline-based information shared within a group and options to join new groups.

- Topics of interest: options to filter content with specific keywords associated with topics of interest (e.g., hobbies, news, channels, habits, etc.).

These options allow controlling the type of social interactions seniors may experience using the portal. For example, people who prefer to join and interact only in group settings should be not diverted by network connections, whereas people who are more concerned about their connections should be able to find them straightforwardly. Alike people should be able to easily explore topics that matter to them based on their specific interests.

The Social Network Integration Manager (SNIM) is responsible for handling the integration of typical SNs to Senior App Suite providing an abstraction mechanism to the rest of the system. When a new SN has to be integrated to the system a new software module is added that interacts with the SNIM by implementing a specific interface (i.e., the SNIM implements a factory design pattern). This interface contains basic SN functionality such as user identification, getting user profile information, obtaining and posting content to the $\mathrm{SN}$, updating user status and writing to contacts. The actual implementation of the interface depends on the capabilities of the specific SN platform. For example, Facebook Graph API [53] is used to read and write to the Facebook social graph.

The Services Integration Manager (SIM) is responsible to integrate services and content from third party sources and provide an abstraction layer to client applications. All services managed by the SIM 
are represented as separate classes and these classes are the abstraction used in Senior App Suite to organize the content provided by the services. When a new service must be integrated a new class must be implemented which loads the content by the external source whenever the service is requested using the proper service integration API. For example, to integrate maps and location services the Google Maps API is used [54], while to integrate YouTube functionality such as channel search, video addition, update or deletion the YouTube Data API is used [55].

The Access Manager ensures that the entrance to the Senior App Suite is allowed only to registered users. The user has to provide a username and password pair to access the portal. By storing the credentials to user's device it is possible to bypass this step on the next time. The credentials can be also stored in a physical security device (e.g., a USB dongle) which when connected to the client computer it launches a browser adding automatically the credentials.

Finally, the Usage Manager module provides statistics on the portal usage (e.g., user demographics, services used, portal access, etc.) by executing queries on the data stored in the database.

\subsection{Security and Privacy}

A secure transport layer protocol (Transport Layer Security-TLS) is used to ensure system security. It provides privacy and encryption of the communication channel between mobile/desktop clients and the server and offers guaranteed authentication and data integrity via cryptography. On the server-side cookies are also used supporting automatic logging in by saving user session. An encryption scheme based on the 2-way Advanced Encryption Standard (AES) algorithm is used to protect username/password information.

The Senior App Suite except from controlling user access and authentication informs users for privacy issues regarding the information they share on social media. In addition a privacy policy statement is provided in the settings section informing the user on the ways the Senior App Suite collects, uses, and manages users' data. It declares that the sole use of personal data is to provide the requested services.

The application supports user control of personal information by providing a section in the settings to define the options of sharing or using private information. The user can set that the content provided could be shared by friends or special groups or specify that the content is private and cannot be shared. Furthermore, several services depend on location information for their operation such as emergency services (i.e., fall detection and SOS messaging) and suggesting nearby points of interest. Location tracking is actually required to be enabled by the user when the android application is installed or when entering the web portal. A user can allow or forbid location access by other users inside a social network.

\section{Evaluation}

A pilot study was conducted to evaluate the developed system in multiple dimensions including usability and acceptability, service usage and attractiveness and well-being, by collecting both qualitative and quantitative data. For the evaluation of the platform 22 seniors ( 9 male, 13 female) from Western Greece Region were involved. The average age was $65.7( \pm 4.6)$ years with a distribution of $52.6 \%$ (60-64 years), 26.3\% (65-69 years) and $21.1 \%$ (70 and over). All participants were in good cognitive functioning with no severe health problems and their education was primary $(15 \%)$, secondary $(64 \%)$ or higher $(21 \%)$. The members of the evaluation user group were different from the members of the design focus group for not biasing the evaluation process. The users used the Senior App Suite in realistic scenarios via a 10-inch tablet with $1.3 \mathrm{GHz}$ processor, 1 GB RAM, 32 GB storage capacity and the Android operating system. The device cost was approximately 250 Euros. Besides the tablet, the infrastructure needed to use the platform was a typical Internet connection. The duration of the pilot was eight weeks, from 27 July to 20 September 2105. The participants provided their feedback through questionnaires and interviews, once in the middle and once more at the end of the pilot. The Western Greece Region Ethics Committee approved the study. 
For the inclusion of the participants, besides the ageing criterion, we took into account their willingness to voluntarily participate in this study. We focused on users with basic knowledge of technology (e.g., can navigate on a simple UI screen or web page after training) and an expressed interest or curiosity to use a digital tool for enhancing social inclusion and well-being. On the other hand technology experienced users who are already using tools or mainstream social networking platforms for communication and interaction may not be interested since they would probably are satisfied with existing systems and tools. More than 40 seniors were screened for eligibility by the study team in call for participation sessions.

All participants were informed about the purpose of the study and the planned evaluation tasks and signed an informed consent. A short training period to familiarize them with the operation of Senior App Suite and the user interface of the various services was allocated. Telephone communication was provided to discuss technical or other issues regarding system usage during the evaluation. Two participants dropped the evaluation study in the first two weeks due to personal or health reasons, so that at the end 20 completed the full pilot tasks with an average usage period of Senior App Suite of 45 days (range $38-56$ days).

\subsection{Usability and Acceptability}

Usability and acceptability are important metrics to examine during the evaluation assessing on the one hand the degree to which the users are able to interact with the system services in an easy-to-use and intuitive manner and on the other hand the degree of the perceived platform usefulness. These metrics can be evaluated by employing tools such as standard questionnaires, interviews and by observing the users while they are using the system.

The main research tool used to evaluate usability and acceptability was the Technology Acceptance Model 3 (TAM3) [56]. TAM3 is an extension of the original TAM model which explored the main factors that affect the acceptance of novel technologies and computer systems [57]. These factors are centered on two main concepts the "perceived ease of use" and the "perceived usefulness". The former reflects the user perception on how easy is to use a specific technology and the later reflects the user perception on the benefits that one can experience by using a specific technology.

We have used question items of TAM3 in the following constructs: Perceived Usefulness (PU), Perceived Ease of Use (PEOU), Computer Self-Efficacy (CSE), Perceptions of External Control (PEC), Computer Playfulness (CPLAY), Computer Anxiety (CANX), Perceived Enjoyment (ENJ), and Output Quality (OUT). Question items were translated to Greek and rephrased to make them relevant to the context of Senior App Suite used by the elderly at home. In total 30 items were used and scored on a 7-point Likert scale (from $1=$ strongly disagree to 7 = strongly agree).

Table 1 shows the descriptive statistics of the TAM3 questionnaire measurements. All internal consistency reliabilities (based on Cronbach' alphas) for all eight constructs were above the recommended cut-off value of 0.70 and thus were considered appropriate for use in the evaluation [58]. Regarding the PU of the Senior App Suite the users moderately agree that using the platform's services does provide an advantage and has positive consequences regarding the supporting of their goals. The PEOU has even higher mean value meaning that the users agree again that the system is easy and intuitive to use. The CSE and the PEC have similar mean values with the PEOU reflecting the fact that the users are satisfied with the means that are available and support their use of the system on a regular basis. The CPLAY has a positive range reflecting the intrinsic motivation of seniors to use the specific system. The CANX value shows that the seniors feel some concern about using the system. This is normal since the elderly often have worries of doing wrong actions while using digital systems. The ENJ designates the degree of feeling pleasance and fun when using the system. Comparing ENJ and CANX we see that the Senior App Suit causes, even marginally, more fun than worry. Finally, the OUT is determinant of the PU and their values are close. 
Table 1. Mean, Standard Deviation and Internal Consistency Reliability of the measurement Constructs and Items.

\begin{tabular}{cccccccccc}
\hline Construct & Items & Mean & SD & ICR & Construct & Items & Mean & SD & ICR \\
\hline PU & 4 & 5.57 & 1.23 & 0.93 & CPLAY & 4 & 5.33 & 1.17 & 0.84 \\
PEOU & 4 & 5.94 & 1.11 & 0.91 & CANX & 4 & 5.48 & 1.26 & 0.88 \\
CSE & 4 & 5.89 & 1.25 & 0.83 & ENJ & 3 & 5.60 & 1.06 & 0.87 \\
PEC & 4 & 5.83 & 1.18 & 0.79 & OUT & 3 & 5.54 & 1.08 & 0.84 \\
\hline
\end{tabular}

\subsection{Service Usage}

Service usage provides the frequency of using each service in Senior App Suite by analyzing the data in system log files and the information gathered by the interviews. According to system logs the most used service categories in all age groups were Information, Reminders and Social Networking. Figure 13a shows service usage by age group. The older age group (70+) has used more frequently the Reminders, Pension Information and the Emergency whereas the younger age groups have used intensively the Information and Social Networking services. Figure 13b shows the percentage of pilot days with service usage by age group. On average, the Senior App Suite services were used about every second day with a lower proportional use in the age group above 70 years. For the whole duration of the pilot consistent usage was observed on the Pension Information service, whereas the other service types showed a gradual drop in usage frequency with Information services having the largest decline. From the service usage analysis it was found that users were using the social networking service three times a week on average.

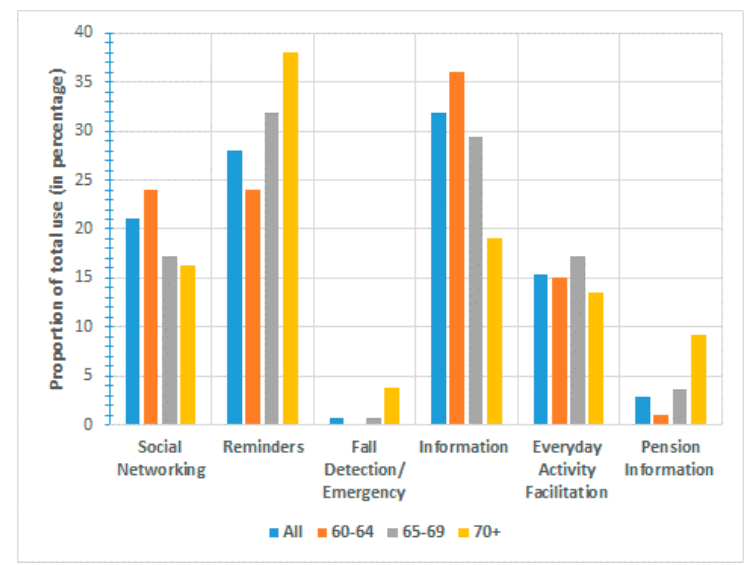

(a)

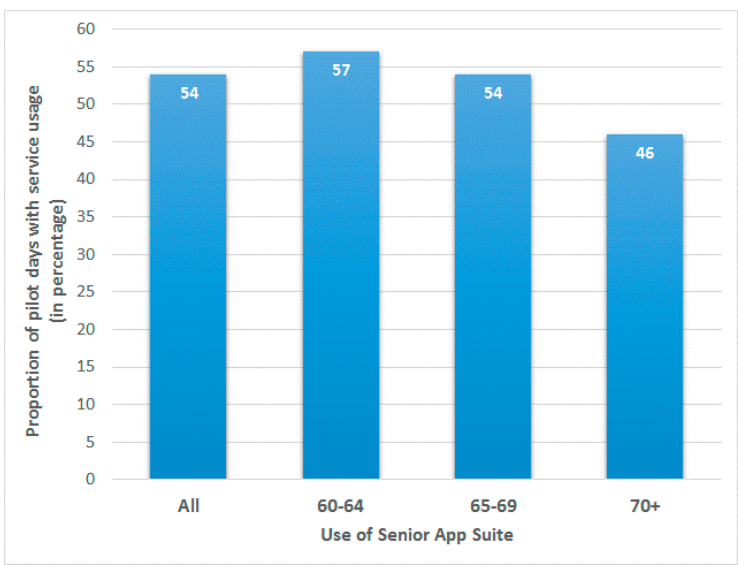

(b)

Figure 13. (a) Service usage as logged by the system classified in various age groups; (b) Overall service use during the pilot period.

The analysis of the logged data indicates that different age groups have different priorities and goals to fulfil in their life. Although fall detection and emergency notification have not been used as much as the other services during the pilot their perceived value is not low. According to the feedback we got from the interviews the users feel more protected when they know that they can notify immediately someone in case of an emergency. Along the same lines pension information usage frequency is determined by its nature as it will be normally needed only twice per month; however its value is considered high, especially among the older age groups.

Service attractiveness was evaluated with interviews at the end of the pilot study with discussions and a ranking process. The findings were in principal consistent with the service usage as evaluated by analyzing the system logs. There was only a difference between the user rating of the services and 
their use in the case of Emergency and Pension Information as mentioned above. The users were very contented by these services and expressed an interest to continue using them after the pilot ending.

\subsection{Well-Being and Loneniness}

The Senior App Suite ultimate goal is to enhance the social inclusion and well-being of seniors by providing specially designed services to prevent loneliness and social isolation. The argument is that seniors who can be more socially connected and are able to interact with family and friends with easy to use tools should feel happier. Measuring, however, the well-being and loneliness is not an easy task. Such states depend on multiple factors such as socioemotional and socioeconmical conditions, social skills and health status. In this study, we have attempted to measure loneliness before and after the pilot by using a questionnaire. In particular, we adopted the Revised UCLA Loneliness Scale (R-UCLA) which is a standard scale for measuring loneliness [59]. There are 20 items which are scored on a 4-point scale coded 1 (Never), 2 (Rarely), 3 (Sometimes) and 4 (Often). Each senior's responses to the questions are summed (half of the items should be reverse scored), with higher scores suggesting greater loneliness.

After collecting the data we performed statistical analysis using the Wilcoxon signed-rank test to explore changes in the R-UCLA. The analysis was performed with SPSS [60]. Table 2 summarizes the R-UCLA Scores before and after the pilot. There was a moderate improvement in R-UCLA from $37.40( \pm 7.21)$ to $36.37( \pm 7.85)$ with $p=0.034$, where loneliness in the sample as whole, nonetheless, was found to be from low to moderate levels. This improvement can only be considered as indicative and we cannot confirm causality due to the limited size of the sample, duration of the pilot and depth of the statistical analysis. However, there is evidence in the literature that the use of social networking systems can have a positive effect on decreasing loneliness among the elderly [61,62].

Table 2. Change in R-UCLA Scores in four of the items and for all items before and after the pilot.

\begin{tabular}{ccccc}
\hline Item & Mean & SD & Mean $^{\text {a }}$ & SD $^{\text {a }}$ \\
\hline I lack companionship & 1.88 & 0.73 & 1.82 & 0.72 \\
I feel left out & 1.85 & 0.71 & 1.81 & 0.74 \\
I feel isolation from others & 1.98 & 0.65 & 1.83 & 0.67 \\
There are people I can turn to $^{\mathrm{b}}$ & 1.76 & 0.60 & 1.75 & 0.62 \\
All items & 37.40 & 7.21 & 36.37 & 7.85 \\
\hline a values after the pilot; $^{\mathrm{b}}$ item that should be reverse scored.
\end{tabular}

The feedback derived from the interviews with the seniors provided similar qualitative evidence. Most of the participants who used actively the social networking services thought that their interaction level with others was increased during the pilot. They emphasized that using the platform services provided to them a new way to communicate, especially with younger members of their family. Other participants really enjoyed the fact that their children found exciting this new endeavor of their parents. The overall feeling was that the participants during the pilot have improved their social interactions in terms of frequency and quality. Besides interacting with family and friends several participants had met together during the pilot preparatory sessions and created a shared activity group that gave them an extra opportunity to interact and be in touch with new friends.

\section{Discussion}

This work has focused on the development and evaluation of an AAL system that supports the needs of older adults with services to address several areas of their everyday living. The evaluation showed that Senior App Suite services were rated positively for usability and acceptability with some of the users creating an increased interest in technology as a consequence of using the system. These findings were in accordance with the self-rating of service attractiveness as given by the interviews and the frequency of service usage as measured by system logs analysis. Based on semi-structured 
interviews the positive factors that influence system acceptance found to be system usefulness, the prospective advantage in the daily life of seniors, the positive inspiration of the study team, and the social influence with respect to pilot participation. The factors with a negative influence identified were technology fear and resistance to change, possible cost of the required infrastructure, privacy infringement and triggering of false emergency alarms.

The use of AAL services by seniors was feasible because accessibility factors have been taken into account through a methodological approach grounded in the principles of human-centered design which led to a simplified interaction model that could be embraced by the targeted users. Another critical factor found to be the training provided to the elderly before the system trial start as well as the technical support service provided through telephone communication during the pilot.

We attempted to study the effect of using specially designed services that assist elderly's social interaction with other people on their quality of life and in particular in terms of loneliness mitigation. The hypothesis is that using such services can be beneficial for decreasing social isolation and loneliness. There is quantitative indication that this assumption is realistic backed up also by the qualitative analysis from the user's feedback derived during the pilot study suggesting that such services can motivate people in new activities, maintain connection with social ties, give joy and self-confidence, and increase the frequency and quality of social interactions. However, the elderly have to be encouraged to use such services. For example, young family members or care givers can inspire, influence and help seniors to use tools for online interactions by creating opportunities in real-life that can have a follow-up in the digital space. Governmental and non-governmental organizations can play a central role here in assisting and encouraging the use of such online tools through social programs that foster awareness and training.

Although our approach shares common goals with the systems presented in the related work section such as provisioning of social networking services, using of ambient technologies to deliver personalized services, creating user interface that is tailored to the elderly needs and integration with third-party services, there are certain extensions that make our contribution different. On a functionality level a richer array of services is provided (see Table 3 for an overview comparison) which can be harnessed to provide in concert a richer experience to seniors. In particular, the pension information service is not found in similar systems, probably because its implementation depends directly on the initiative of public sector services and because of security issues arising from the management of personal data. Regarding the underlying architecture, instead of supporting point solutions, especially with respect to social networking services, the proposed abstractions entailed a flexible service-oriented framework with advanced features. The developed framework supports functionality versatility and component reutilization to enable easy integration of a variety of services spanning different AAL application areas, and makes special purpose services such as access to pension systems easy to deploy. Finally, the wider and conceptually sound approach taken on system evaluation supersedes the typical qualitative data analysis followed by the researched systems and thus conveys more solid conclusions on the merit of the proposed solution.

Fall detection usefulness has been rated high both at the system design phase and during the system evaluation. This indicates that services enhancing the feeling of safety are well accepted even when there are limitations associated with their use. In Senior App Suite the use of this service requires that the senior carries with him/her the device all the time and this is a strong limitation. Furthermore, using a threshold-based algorithm mainly fast falls can be detected accurately. There are, of course, other patterns of falls often experienced by older people like slow falls due to dizziness or sliding from a chair when trying to stand up. However, such challenging falls require a more advanced system which may include at least three accelerometers affixed in different places of the body and data mining algorithms to recognize postures that may be the result of a fall. To make our approach more viable, a low-cost smart watch can be used to gather accelerometer signals in combination with an Android mobile device that can process the transmitted data streams to recognize falls using the methodology described in this paper. 
Limitations of the evaluation study are acknowledged. Although the sample has been attempted to be representative regarding the socioeconomic and education background of the participants, the statistical significance of the results would have been more valid with a larger sample size. Similarly, a larger duration of the pilot would have made the conclusions more rigorous. Finally, because of lack of a control group we cannot be sure whether the improvement of the seniors regarding the loneliness measurement occurred as a consequence of the Senior App Suite use.

Table 3. Comparing Senior App Suite Features with other AAL systems.

\begin{tabular}{ccccccccc}
\hline AAL System & SN & A/MR & FD & I & EAF & PI & SOS & Technology \\
\hline WeCare & Yes & Yes & - & +++ & +++ & - & - & Web \\
AMCOSOP & Yes & Yes & - & ++ & ++ & - & - & Web \\
Go-myLife & Yes & Yes & - & ++ & ++ & - & - & Web/Mob \\
SI-Screen & Yes & Yes & - & ++ & +++ & - & - & Web/Mob \\
JOIN-IN & Yes & - & - & ++ & +++ & - & - & Web \\
SoMedAll & Yes & Yes & - & ++ & ++ & - & - & Web \\
Elder Spaces & Yes & Yes & - & ++ & ++ & - & - & Web \\
Oscar Senior & Yes & Yes & - & ++ & +++ & - & - & Mob \\
Seniors Phone & Yes & - & - & + & ++ & - & Yes & Mob \\
Senior App Suite & Yes & Yes & Yes & +++ & +++ & Yes & Yes & Web/Mob \\
\hline
\end{tabular}

$\mathrm{SN}=$ Social Networking, A/MR = Activity/Medicine Reminder, FD = Fall Detection, I = Information (welfare, news, channels, weather, maps, translator), EAF = Everyday Activity Facilitation (calling, shopping, commuting, entertainment, e-payments), PI = Pension Information, SOS = Emergency Button.

Supporting voice commands is a feature that will enhance user interaction with Senior App Suite as indicated by the design questionnaire $(60.8 \%$ of the participants considered that this is a useful characteristic). Especially for users with severe health problems such as low vision, speech recognition integration facilitates the use of mobile devices and applications. However the integration of continuous speech recognition on mobile devices is a challenge for many reasons, such as the large number of vocabularies and dialects, the noisy conditions as one moves and because the input can be unpredictable. Furthermore, such an implementation is likely to stream audio to remote servers, which could lead to significant amount of resources consumption (e.g., battery and bandwidth).

\section{Conclusions}

This paper described the development and evaluation of a system that provides a suite of services to assist and encourage its users to remain socially active (e.g., establishing and maintaining social networks, showing social events), to strengthening their sense of safety and autonomy (e.g., emergency button, fall detection, medication reminder) and to provide targeted information (e.g., welfare, pension, weather, news, etc.). Our findings are aligned with recommendations previously reported by scholars involved with analogous research and refine their guidelines by addressing open issues identified in related technologies. Our main conclusions can be summarized as follows:

- Adopting human centered design approach was crucial in order to design a system that takes into account the special needs of elderly and is user-friendly.

- Context information (e.g., location, acceleration) allowed the provision of value added services to the users.

- User control on personal information, data security mechanisms and privacy policies are critical elements in the design of a system that is addressed to people that have an a priori feeling of worry for the technology.

- Usability and accessibility of the system was validated by real users $(n=22)$ in a pilot study of eight weeks with positive results. 
- The well-being in terms of loneliness was measured before and after the trial and found to have been improved but this should be validated over a longer period of time and with a larger user sample.

- The majority of participants declared that they would be willing to subscribe for accessing such on-line services paying a small monthly fee indicating the business opportunities of Senior App Suite.

Acknowledgments: Part of this research has been co-financed by the European Union (European Social Fund-ESF) and Greek national funds through the Operational Program "DEPIN" of the National Strategic Reference Framework (NSRF) (Project code: 465435).

Author Contributions: C.G. conceived the research concept and supervised system design and experiments setup; I.P. and A.S. contributed to the development of tools and the implementation of experiments; C.G. analyzed the data; C.G. wrote the paper.

Conflicts of Interest: The authors declare no conflict of interest. The founding sponsors had no role in the design of the study; in the collection, analyses, or interpretation of data; in the writing of the manuscript, and in the decision to publish the results.

\section{Appendix A}

Design Questionnaire of the Senior App Suite. *Required

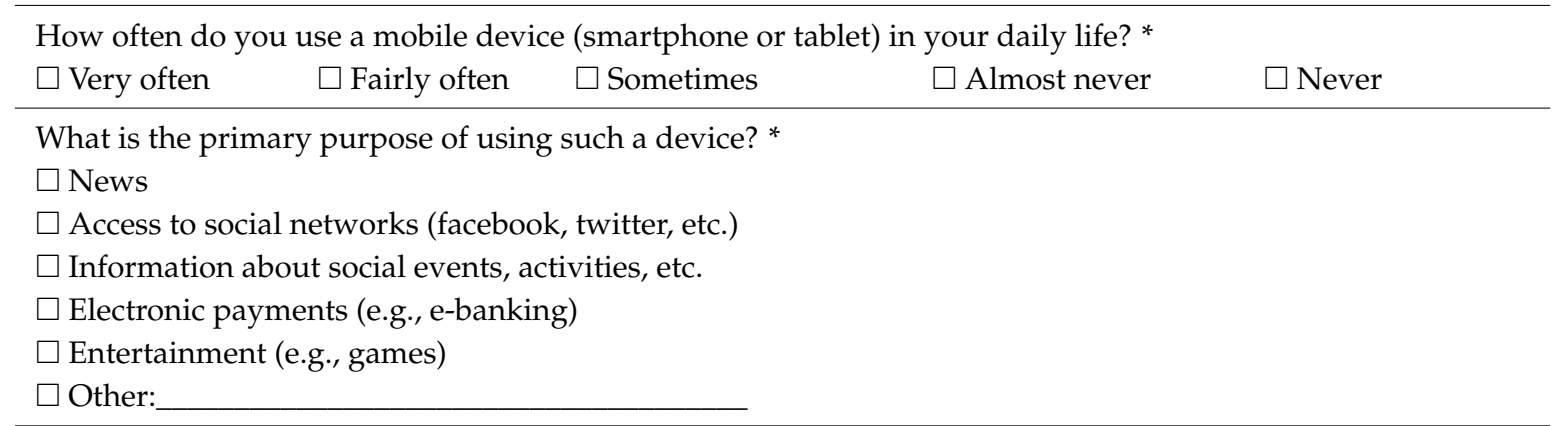

Having services (as those mentioned above) assembled into a single place and accessed whenever needed, instead of separately looking for them online, would be useful. *

\begin{tabular}{|c|c|c|c|}
\hline$\square$ Strongly agree & $\square$ Agree & $\begin{array}{l}\square \text { Neither agree or } \\
\text { disagree }\end{array}$ & $\square$ Disagree \\
\hline
\end{tabular}

\footnotetext{
System services

What services would you prefer to have in a web portal? *

$\square$ News

$\square$ Access to social networks (facebook, twitter, etc.)

$\square$ Information about social events, activities, etc.

$\square$ Electronic payments (e.g., e-banking)

$\square$ Entertainment (e.g., games)

$\square$ Other:
}

\begin{tabular}{|c|c|c|c|c|}
\hline \multicolumn{5}{|c|}{ A medication reminder service would be useful. * } \\
\hline$\square$ Strongly agree & $\square$ Agree & $\begin{array}{l}\square \text { Neither agree or } \\
\text { disagree }\end{array}$ & $\square$ Disagree never & $\begin{array}{l}\square \text { Strongly } \\
\text { disagree }\end{array}$ \\
\hline \multicolumn{5}{|c|}{ A fall detection service and subsequent automatic notification of relatives or friends would be useful. } \\
\hline$\square$ Strongly agree & $\square$ Agree & $\begin{array}{l}\square \text { Neither agree or } \\
\text { disagree }\end{array}$ & $\square$ Disagree never & $\begin{array}{l}\square \text { Strongly } \\
\text { disagree }\end{array}$ \\
\hline \multicolumn{5}{|c|}{ The system should provide reminders for scheduled activities and important events * } \\
\hline$\square$ Strongly agree & $\square$ Agree & $\begin{array}{l}\square \text { Neither agree or } \\
\text { disagree }\end{array}$ & $\square$ Disagree & $\begin{array}{l}\square \text { Strongly } \\
\text { disagree }\end{array}$ \\
\hline
\end{tabular}




\begin{tabular}{|c|c|c|c|c|}
\hline$\square$ Strongly agree & $\square$ Agree & $\begin{array}{l}\square \text { Neither agree or } \\
\text { disagree }\end{array}$ & $\square$ Disagree & $\begin{array}{l}\square \text { Strongly } \\
\text { disagree }\end{array}$ \\
\hline \multicolumn{5}{|c|}{ Other services you would like to have in such a system? } \\
\hline \multicolumn{5}{|c|}{ Desirable features for an older adult support application } \\
\hline \multicolumn{5}{|c|}{ For a mobile application (e.g. tablet, smartphone app) } \\
\hline \multicolumn{5}{|c|}{ Icons and menus should be in large size to make it easy to navigate and operate the application * } \\
\hline$\square$ Strongly agree & $\square$ Agree & $\begin{array}{l}\square \text { Neither agree or } \\
\text { disagree }\end{array}$ & $\square$ Disagree & $\begin{array}{l}\square \text { Strongly } \\
\text { disagree }\end{array}$ \\
\hline \multicolumn{5}{|c|}{ Receive feedback in case of wrong interaction * } \\
\hline$\square$ Strongly agree & $\square$ Agree & $\begin{array}{l}\square \text { Neither agree or } \\
\text { disagree }\end{array}$ & $\square$ Disagree & $\begin{array}{l}\square \text { Strongly } \\
\text { disagree }\end{array}$ \\
\hline \multicolumn{5}{|c|}{ Use voice commands * } \\
\hline$\square$ Strongly agree & $\square$ Agree & $\begin{array}{l}\square \text { Neither agree or } \\
\text { disagree }\end{array}$ & $\square$ Disagree & $\begin{array}{l}\square \text { Strongly } \\
\text { disagree }\end{array}$ \\
\hline $\begin{array}{l}\text { Preferable device } \\
\square \text { Tablet } \\
\square \text { Smartphone } \\
\square \text { Both }\end{array}$ & using the $\mathrm{c}$ & & & \\
\hline
\end{tabular}

Other desirable features

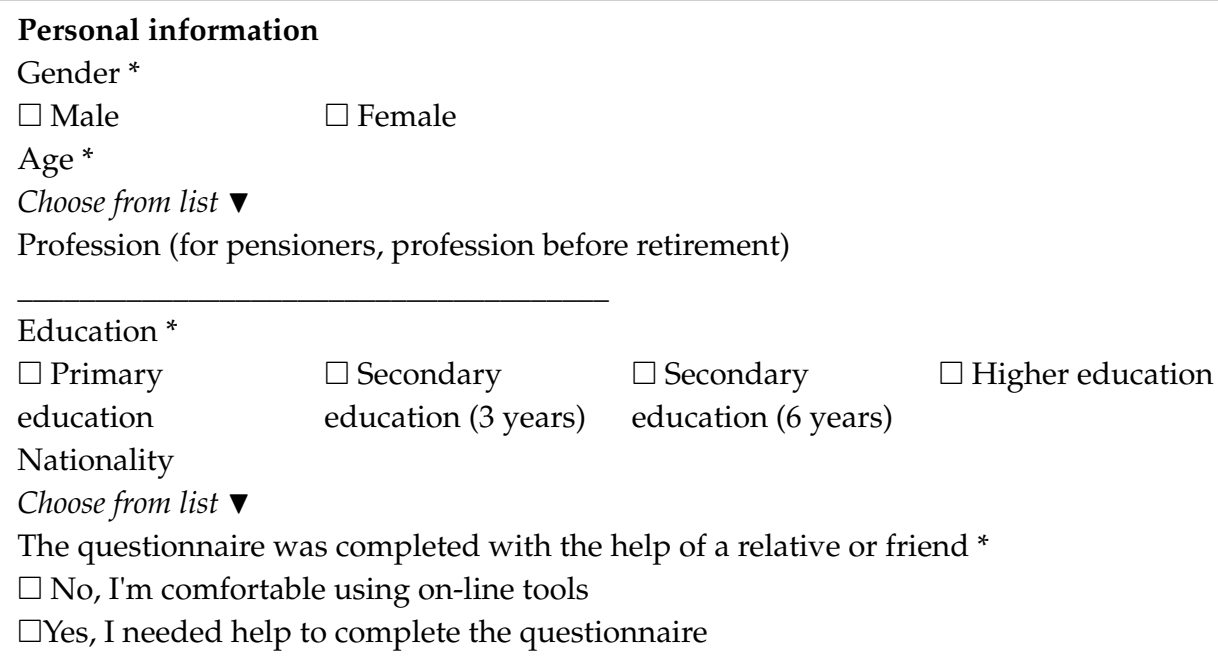

\section{References}

1. United Nations Department of Economic and Social Affairs. World Population Ageing 2013. Available online: http://www.un.org/en/development/desa/population/publications/pdf/ageing/ WorldPopulationAgeing2013.pdf (accessed on 18 May 2017).

2. Mayes, D.G.; Berghman, J.; Salais, R. Social Exclusion and European Policy; Edward Elgar: Cheltenham/Northampton, MA, USA, 2001.

3. Popay, J.; Escorel, S.; Hernández, M.; Johnston, H.; Mathieson, J.; Rispel, L. Understanding and Tackling Social Exclusion: Final Report to the WHO Commission on Social Determinants of Health; Report of the Social Exclusion Knowledge Network; World Health Organization: Geneva, Switzerland, 2008.

4. Borglin, G.; Edberg, A.; Hallberg, I.R. The experience of quality of life among older people. J. Aging Stud. 2005, 19, 201-220. [CrossRef] 
5. Giles, L.C.; Glonek, G.F.; Luszcz, M.A.; Andrews, G.R. Effect of social networks on 10 year survival in very old Australians: The Australian longitudinal study of aging. J. Epidemiol. Community Health 2005, 59, 574-579. [CrossRef] [PubMed]

6. Gabriel, Z.; Bowling, A. Quality of life in old age from the perspectives of older people. In Growing Older: Quality of Life in Old Age; Walker, A., Hennessy, C.H., Eds.; Open University Press: Maidenhead, UK, 2004; pp. 14-34.

7. Leist, A.K. Social media use of older adults: A mini-review. Gerontology 2013, 59, 378-384. [CrossRef] [PubMed]

8. Rashidi, P.; Mihailidis, A. A survey on ambient-assisted living tools for older adults. IEEE J. Biomed. Health Inform. 2013, 17, 579-590. [CrossRef] [PubMed]

9. Vetere, F.; Davis, H.; Gibbs, M.; Howard, S. The magic box and collage: Responding to the challenge of distributed intergenerational play. Int. J. Hum. Comput. Stud. 2009, 67, 165-178. [CrossRef]

10. Röcker, C.; Ziefle, M.; Holzinger, A. Social inclusion in ambient assisted living environments: Home automation and convenience services for elderly users. In Proceedings of the International Conference on Artificial Intelligence, Las Vegas, NV, USA, 18-20 July 2011; pp. 55-59.

11. Wada, K.; Ikeda, Y.; Inoue, K.; Uehara, R. Development and preliminary evaluation of a caregiver's manual for robot therapy using the therapeutic seal robot Paro. In Proceedings of the 19th International Symposium in Robot and Human Interactive Communication, Viareggio, Italy, 13-15 September 2010; pp. 533-538.

12. Mubashir, M.; Shao, L.; Seed, L. A survey on fall detection: Principles and approaches. Neurocomputing 2013, 100, 144-152. [CrossRef]

13. Qudah, I.; Leijdekkers, P.; Gay, V. Using mobile phones to improve medication compliance and awareness for cardiac patients. In Proceedings of the 3rd International Conference on PErvasive Technologies Related to Assistive Environments, Samos, Greece, 23-25 June 2010; pp. 1-7.

14. Vuong, N.K.; Chan, S.; Lau, C.T.; Lau, K.M. Feasibility study of a real-time wandering detection algorithm for dementia patients. In Proceedings of the First ACM MobiHoc Workshop on Pervasive Wireless Healthcare, Paris, France, 16 May 2011; pp. 1-4.

15. Charness, N.; Boot, W.R. Aging and information technology use: Potential and barriers. Curr. Dir. Psychol. Sci. 2009, 18, 253-258. [CrossRef]

16. García-Peñalvo, F.J.; Conde, M.Á.; Matellán-Olivera, V. Mobile apps for older users-The development of a mobile apps repository for older people. In Learning and Collaboration Technologies. Technology-Rich Environments for Learning and Collaboration; Zaphiris, P., Ioannou, A., Eds.; Springer: Berlin/Heidelberg, Germany, 2014; Volume 8524, pp. 117-126.

17. Lorenz, A.; Oppermann, R. Mobile health monitoring for the elderly: Designing for diversity. Pervasive Mob. Comput. 2009, 5, 478-495. [CrossRef]

18. Díaz-Bossini, J.M.; Moreno, L. Accessibility to mobile interfaces for older people. Proced. Comput. Sci. 2014, 27, 57-66. [CrossRef]

19. van den Broek, G.; Cavallo, F.; Wehrmann, C. AALIANCE Ambient Assisted Living Roadmap; IOS Press: Amsterdam, The Netherlands, 2010.

20. Ambient Assisted Living Joint Programme, ICT for Ageing Well. Catalogue of Projects. Available online: http://www.aal-europe.eu/wp-content/uploads/2015/09/15--1805_AAL_Catalogue_ 2015_ONLINE.pdf (accessed on 18 May 2017).

21. Steen, M.G.D.; Ervasti, M.; Harjumaa, M.; Bourke, S.; Hernandez, V.; Min, M.; Prins, S. WeCare: Cooperating with older people in the design and evaluation of online social networking services. In Ambient Assisted Living; Garcia, N.M., Rodrigues, J.J., Eds.; CRC Press: Boca Raton, FL, USA, 2015; pp. 647-676.

22. Pensas, H.; Liolis, K.; Kouvatseas, G.; Vainio, A.M.; Wimmer, B.; Kaila, L.; Kivimäki, T.; Laitinen, S.; Vanhala, J. AMCOSOP: A social networking system for the elderly. In Proceedings of the 15th International Academic MindTrek Conference: Envisioning Future Media Environments, Tampere, Finland, 28-30 September 2011; pp. 329-331.

23. Kivimäki, T.; Kölndorfer, P.; Vainio, A.M.; Pensas, H.; Vuorela, T.; Garschall, M.; Vanhala, J. User interface for social networking application for the elderly. In Proceedings of the 6th International Conference on Pervasive Technologies Related to Assistive Environments, Rhodes, Greece, 29-31 May 2013. 
24. Haritou, M.; Anastasiou, A.; Schwarz-Woelzl, M.; Holocher-Ertl, T.; Mulquin, M.; Olalde, I.; Kouris, I.; Koutsouris, D.D. A context-aware social networking platform built around the needs of elderly users: The Go-myLife experience. In mHealth Ecosystems and Social Networks in Healthcare; Lazakidou, A., Zimeras, S., Iliopoulou, D., Koutsouris, D.D., Eds.; Springer International Publishing: Cham, Switzerland, 2016; pp. 119-135.

25. Burkhard, M.; Koch, M. Social interaction screen. Making social networking services accessible for elderly people. i-com Zeitschrift Interakt. Kooperat. Medien 2012, 11, 3-7. [CrossRef]

26. Cantwell, D.; Broin, D.O.; Palmer, R.; Doyle, G. Motivating elderly people to exercise using a social collaborative exergame with adaptive difficulty. In Proceedings of the 6th European Conference on Games Based Learning, Cork, Ireland, 4-5 October 2012; p. 615.

27. Petäkoski-Hult, T.; Vainikainen, S.; Kurki, M.; Lehtinen, L.; Bosco, F. OWELA (Open WEb LAb) as a tool in the SOMEDALL project. In Proceedings of the 4th AAL Forum, Eindhoven, The Netherlands, 24-27 September 2012; pp. 547-551.

28. Leal, A.S.; Bogi, A. Good Practices Handbook. Available online: http://cordis.europa.eu/docs/projects / cnect/8/297298/080/deliverables/001-D37GoodPracticeHandbook.pdf (accessed on 18 May 2017).

29. Oscar Senior. Available online: http:/ / www.oscarsenior.com/ (accessed on 18 May 2017).

30. Seniors Phone. Available online: http://www.seniorsphone.mobi/ (accessed on 18 May 2017).

31. Casas, R.; Marín, R.B.; Robinet, A.; Delgado, A.R.; Yarza, A.R.; Mcginn, J.; Picking, R.; Grout, V. User modelling in ambient intelligence for elderly and disabled people. In Computers Helping People with Special Needs; Miesenberger, K., Klaus, J., Zagler, W., Karshmer, A., Eds.; Springer: Berlin/Heidelberg, Germany, 2008; Volume 5105, pp. 114-122. [CrossRef]

32. Röcker, C. User-centered design of intelligent environments: Requirements for designing successful ambient assisted living systems. In Proceedings of the Central European Conference of Information and Intelligent Systems, Varazdin, Croatia, 18-20 September 2013; pp. 4-11.

33. Wever, R.; van Kuijkb, J.; Boks, C. User-centred design for sustainable behaviour. Int. J. Sustain. Eng. 2008, 1, 9-20. [CrossRef]

34. International Organization for Standardization (ISO). ISO 9241-210:2010_Ergonomics of Human-System Interaction-Part 210: Human-Centred Design for Interactive Systems; ISO: Geneva, Switzerland, 2010.

35. ELDER TABLET Project Website. Available online: http://daisy.cti.gr/eltab/ (accessed on 18 May 2017).

36. Hausdorff, J.M.; Rios, D.A.; Edelber, H.K. Gait variability and fall risk in community-living older adults: A 1-year prospective study. Arch. Phys. Med. Rehabil. 2001, 82, 1050-1056. [CrossRef] [PubMed]

37. Sterling, D.A.; O'Connor, J.A.; Bonadies, J. Geriatric falls: Injury severity is high and disproportionate to mechanism. J. Trauma 2001, 50, 116-119. [CrossRef] [PubMed]

38. Ambient Assisted Living and Well Being. Available online: https://www.facebook.com/ ambientassistedlivingwellbeing/ (accessed on 18 May 2017).

39. Senior Citizens Support Group. Available online: https://www.facebook.com/thescsg/ (accessed on 18 May 2017).

40. Friends of the Elderly. Available online: https://www.facebook.com/FriendsElderly/ (accessed on 18 May 2017).

41. Lee, Y.S. Older Adults' User Experiences with Mobile Phones: Identification of User Clusters and User Requirements. Ph.D. Thesis, Virginia Polytechnic Institute and State University, Blacksburg, VA, USA, 3 September 2007.

42. Shneiderman, B.; Plaisant, C.; Cohen, M.S.; Jacobs, S.M.; Elmqvist, N.; Diakopoulos, N. Designing the User Interface: Strategies for Effective Human-Computer Interaction, 6th ed.; Pearson: Upper Saddle River, NJ, USA, 2016.

43. Hawthorn, D. Possible implications of aging for interface designers. Interact. Comput. 2000, 12, 507-528. [CrossRef]

44. Lin, C.J.; Hsieh, T.L.; Shiang, W.J. Exploring the interface design of mobile phone for the elderly. In International Conference on Human Centered Design; Kurosu, M., Ed.; Springer: Berlin/Heidelberg, Germany, 2009; Volume 5619, pp. 476-481.

45. Ziefle, M.; Bay, S. How older adults meet complexity: aging effects on the usability of different mobile phones. Behav. Inf. Technol. 2005, 24, 375-389. [CrossRef] 
46. Darroch, I.; Goodman, J.; Brewster, S.; Gray, P. The effect of age and font size on reading text on handheld computers. In Human-Computer Interaction-Interact 2005; Costabile, M.F., Paternò, F., Eds.; Springer: Berlin/Heidelberg, Germany, 2005; Volume 3585, pp. 253-266.

47. W3C: Web Content Accessibility Guidelines 2.0. Available online: http://www.w3.org/TR/WCAG20/ (accessed on 18 May 2017).

48. Rello, L.; Pielot, M.; Marcos, M.C. Make it big! The effect of font size and line spacing on online readability. In Proceedings of the 2016 CHI Conference on Human Factors in Computing Systems, Santa Clara, CA, USA, 7-12 May 2016; pp. 3637-3648.

49. Facebook App Development. Available online: https://developers.facebook.com/docs/apps (accessed on 18 May 2017).

50. Erl, T. Service-Oriented Architecture: Concepts, Technology, and Design; Prentice Hall: Upper Saddle River, NJ, USA, 2005.

51. Costello, C. Elgg 1.8 Social Networking; Packt Publishing Ltd.: Birmingham, UK, 2012.

52. Elgg Social Network Engine. Available online: https://elgg.org/ (accessed on 18 May 2017).

53. Facebook Graph API. Available online: https://developers.facebook.com/docs/graph-api (accessed on 18 May 2017).

54. Google Maps API. Available online: https://developers.google.com/maps/ (accessed on 18 May 2017).

55. YouTube Data API. Available online: https://developers.google.com/youtube/v3/ (accessed on 18 May 2017).

56. Venkatesh, V.; Bala, H. Technology acceptance model 3 and a research agenda on interventions. Decis. Sci. 2008, 39, 273-315. [CrossRef]

57. Davis, F.D.; Bagozzi, R.P.; Warshaw, P.R. User acceptance of computer technology: A comparison of two theoretical models. Manag. Sci. 1989, 35, 982-1003. [CrossRef]

58. Hair, J.F.; Black, W.C.; Babin, B.J.; Anderson, R.E.; Tatham, R.L. Multivariate Data Analysis, 7th ed.; Pearson/Prentice Hall: Upper Saddle River, NJ, USA, 2010.

59. Russell, D.; Peplau, L.A.; Cutrona, C.E. The revised UCLA Loneliness Scale: Concurrent and discriminant validity evidence. J. Pers. Soc. Psychol. 1980, 39, 472-480.

60. Pallant, J. SPSS Survival Manual; McGraw-Hill Education: Milton Keynes, UK, 2013.

61. Cotten, S.R.; Anderson, W.A.; McCullough, B.M. Impact of internet use on loneliness and contact with others among older adults: Cross-sectional analysis. J. Med. Internet Res. 2013, 15, e39. [CrossRef] [PubMed]

62. Jones, R.B.; Ashurst, E.J.; Atkey, J.; Duffy, B. Older people going online: Its value and before-after evaluation of volunteer support. J. Med. Internet Res. 2015, 17, e122. [CrossRef] [PubMed] 